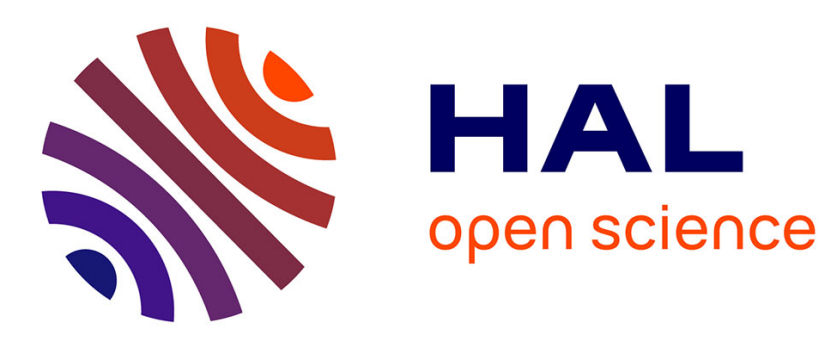

\title{
Advances in the Use of Microfluidics to Study Crystallization Fundamentals
}

Nadine A Candoni, Romain Grossier, Mehdi Lagaize, Stéphane Veesler

\section{To cite this version:}

Nadine A Candoni, Romain Grossier, Mehdi Lagaize, Stéphane Veesler. Advances in the Use of Microfluidics to Study Crystallization Fundamentals. Annual Review of Chemical and Biomolecular Engineering, 2019, 10 (1), pp.59-83. 10.1146/annurev-chembioeng-060718-030312 . hal-01959318

\section{HAL Id: hal-01959318 https://hal.science/hal-01959318}

Submitted on 18 Dec 2018

HAL is a multi-disciplinary open access archive for the deposit and dissemination of scientific research documents, whether they are published or not. The documents may come from teaching and research institutions in France or abroad, or from public or private research centers.
L'archive ouverte pluridisciplinaire HAL, est destinée au dépôt et à la diffusion de documents scientifiques de niveau recherche, publiés ou non, émanant des établissements d'enseignement et de recherche français ou étrangers, des laboratoires publics ou privés. 


\title{
Advances in the Use of Microfluidics to Study Crystallization Fundamentals
}

\author{
Nadine Candoni ${ }^{1}$, Romain Grossier ${ }^{1}$, Mehdi Lagaize ${ }^{1}$, Stéphane Veesler ${ }^{1}$ \\ ${ }^{1}$ Aix-Marseille Université, CNRS, CINaM UMR 7325, 13288 Marseille, France
}

Corresponding author : Nadine CANDONI : candoni@cinam.univ-mrs.fr

\begin{abstract}
Other authors :
Romain GROSSIER : grossier@cinam.univ-mrs.fr

Mehdi LAGAIZE : lagaize@cinam.univ-mrs.fr

Stéphane VEESLER : veesler@cinam.univ-mrs.fr
\end{abstract}

\section{Keywords}

Phase diagram, Polymorphism, Solubility, Screening, Optimization, Xray-diffraction

\begin{abstract}
This review compares droplet-based microfluidic systems used to study crystallization fundamentals in chemistry and biology. An original high-throughput droplet-based microfluidic platform is presented. It uses $\mathrm{nL}$ droplets, generates a "chemical library" and directly solubilizes powder, thus economizing both material and time. It is compatible with all solvents without the need for surfactant. Its flexibility permits phase diagram determination and crystallization studies (screening and optimizing experiments), and makes it easy to use for non-specialists in microfluidics. Moreover, it allows concentration measurement via UV spectroscopy and solid characterization via $X R D$ analysis.
\end{abstract}




\section{INTRODUCTION}

Crystallization is used in chemistry and biology for molecule separation, purification processes, for control of product properties and for analytical purposes (1). For instance, protein crystallization is a key step in the determination of the threedimensional structure of proteins by X-ray diffraction (XRD), allowing a better understanding of their biological functions (2). In pharmaceutical applications, there may be a wide variety of solid forms may appear such as polymorphs, solvates, microcrystalline solids and amorphs (3). Crystal properties are influenced by many parameters such as temperature, solute concentration, chemical composition and hydrodynamics.

In crystallization from solution, the first step, nucleation, is fundamental in determining the physical properties of crystals, such as size distribution and phases (4). However, nucleation is a stochastic phenomenon requiring numerous experiments to obtain reliable data $(5,6)$.

Crystallization studies are generally performed in milli- or micro-reactors $(5,7,8)$. However, using these large volumes has two drawbacks: first, the crystals need to be located in space and in time in order to follow their formation. Second, a large quantity of raw material is required for statistics to obtain reliable data.

The unpredictability of nucleation can be addressed by reducing the volume of crystallization, making observation possible at the micrometer scale, and thus increasing the resolution of detection with an optical microscope, for instance. Moreover, identifying the conditions required to obtain crystals usually involves screening crystallization conditions and then optimizing one of them. This volume reduction is particularly advantageous with molecules that are expensive to produce and of limited availability. However, reducing the volume of reactors considerably 
increases the surface/volume ratio of the solution and the effect of evaporation becomes non-negligible.

One way to control evaporation is to surround each small reactor with a non-miscible liquid, as in micro-emulsions, and/or with non-porous solids, as in micro-channels, and/or with gels of well-controlled micro-porosity. In the past decade, microfluidic tools to control and manipulate flows at sub-millimeter scale, have increasingly been used in a lab-on-chip approach (9). This has allowed the number of experiments to be increased and the amount of material to be decreased (9-11). Microfluidics holds great promise for the control and the study of crystallization processes, for instance, producing crystals of controlled size (12). A very large number of microfluidic systems dedicated to the screening of crystallization conditions is available, based on different crystallization methods (2): free interface diffusion $(13,14)$, counter diffusion $(15,16)$, vapor diffusion $(17,18)$, batch $(19,20)$.

The present review covers droplet-based microfluidic crystallization techniques, which are generally miniaturized versions of the micro-batch method, i.e. mixing the solution containing the molecule of interest with solvent or buffer and/or anti-solvent and/or crystallization agent inside droplets generated in oil (21-24). In addition to technical considerations, this review focuses on their contribution to crystallization fundamentals: nucleation studies, screening and optimizing crystallization conditions, determining phase diagrams and studying polymorphism and structure of crystals.

\section{DROPLET-BASED MICROFLUIDIC SYSTEMS}

Various droplet-based microfluidic systems for crystallization studies are aimed at competing with high-throughput robots to screen crystallization conditions of biomolecules (proteins or active pharmaceutical ingredients). Thus, the microfluidic 
chip displays many integrated functions involved in automatized and complex manipulations of fluids, as in the platform developed by Perry et al. (14) (Figure 1). This means that droplet-based microfluidic systems offer the advantages of highthroughput, low sample and reagent consumption, rapid mixing and minimal crosscontamination. However, despite the spectacular achievements in crystallization obtained thereby, several drawbacks remain.

1. These microfluidic chips rely mainly on microfabrication technologies such as softlithography, high-resolution stereo-lithography and 3D print techniques. Most chips are for single use and require complex equipment (integrated valves and pumps, mixers, especially designed and micro-fabricated micro-channels or chambers, multiple arrivals of pressurized gas). However, microfabrication processes can be expensive and time-consuming, requiring specialist infrastructure and extensive handling.

2. Currently used chip materials such as silicone (25), glass (25), hydrogels (26) and elastomers $(27,28)$ are not fully compatible with all crystallization solvents. For example, PDMS (polydimethylsiloxane), the most frequently used material, is not compatible with organic solvents such as acetone. Moreover, solvent may evaporate due to the permeability of the polymer.

3. The imposed channel network geometry makes it difficult to modify the setup, rendering it less accessible to non-specialists.

4. Liquid-handling at microfluidic scale is very sensitive to liquid properties such as flow viscosity and surface tension. Hence, system calibration is obligatory for each working fluid. This can be very difficult when handling liquids with high viscosity (i.e. PEG (polyethylene glycol)) or low surface tension (i.e. detergent used for solubilization of membrane protein). It is also the main reason why most of the current droplet methods 
rely on surfactant use. However, surfactants can interfere with the solute molecules, which affects crystallization.

To address these drawbacks, we developed a platform using commercially available and combinable modules $(21,29-32)$, rendering the setup easy to use for nonspecialists in microfluidics. The junctions and the tubing used to generate droplets are compatible with almost all solvents, showing excellent resistance and no solvent evaporation (31). In addition, mixing of liquids, detection of droplets and their concentration and storage are performed independently, so the platform is flexible (Figure 2). It is used to investigate crystallization of various molecules: proteins in aqueous and viscous solutions like lysozyme (21, 22, 29-31, 33), rasburicase (23) and human quinone reductase 2 (QR2) $(30,32)$, organic molecules like caffeine in isonicotinamide (21), glyclazide in isopropanol and paracetamol in water, in acetonitrile and in isopropanol (34).

All crystallization applications require crystals of suitable quality and size. The major challenge lies in monitoring and controlling the crystallization process. As no theory is available to predict in which environment or under what conditions a new molecule can successfully be crystallized, two steps are generally followed: screening for favorable crystallization conditions and subsequent optimizing of crystal growth. Moreover, for each experimental condition, droplets generated as nano-reactors have to be homogeneous (in composition, size and frequency). In the following, droplet-based microfluidic systems are compared in terms of generation of homogeneous droplets to determine the phase diagram, study polymorphism, screen and optimize crystallization conditions for crystal structure analysis. 


\section{DROPLETS AS NANO-REACTORS FOR CRYSTALLIZATION STUDIES}

In crystallization studies, the solute is generally mixed with one component and/or gradients of concentration are generated. In droplet-based microfluidic systems, the channel is filled with different batches of mono-concentrated droplets, the chemical composition being varied using a multi-channel syringe pump and controlling the relative flow rates of the different solutions upstream of the junctions. Depending on the flow rate, droplets of different chemical compositions are generated. As suggested by Li et al.(9), droplet composition is linked to size and frequency. Therefore, controlling size and frequency is key in microfluidic systems.

\section{III.1. Controlling size and frequency of droplets:}

Droplets of the liquid containing the solute are generated by injecting it (dispersed flow) together with a non-miscible liquid (continuous flow) into junctions. Many experiments and simulations investigate the size (length $L$ ) and frequency of droplets through phase properties (viscosity $(35-43)$ and interfacial energy $(35,36,43)$ ), channel geometry (the height and the width of the channels essentially in planar geometries with rectangular cross-sections $(34,40-42,44))$ and operating parameters (flow rate ratio $(35-41,45$ 48)). Few studies deal with cylindrical channels.

In a cross-junction mixing two dispersed flows, an interface is observed in the droplet while it forms (29) (Figure 3a). The two dispersed flows can be assumed to be Newtonian. As flows are laminar and convection-free due to negligible gravity (49), mixing proceeds solely by diffusion at the interface. Mixing time inside droplets is described by $t_{\operatorname{mix}}=\left.s t\right|^{2} / 2 \mathrm{D}$, where stl is the striation length, correlated with $\mathrm{W}$ the tubing inner diameter and $\mathrm{D}$ the diffusion coefficient (50). Mixing in droplets after their breakup is accelerated by droplets twirling (46) with the continuous flow, however only when 
droplets are spherical. Figure $\mathbf{3 b}$ shows that the mixing time is 4 -fold longer in elongated droplets ( $L>>W)$ (Figure 3b1) than in spherical ones $(L=W)$ (Figure 3b2). Hence, droplet size should be determined by the specific objective of the crystallization: optimal crystal quality requires a long diffusion time and a convection-free medium, which means elongated droplets $(L / W>2)$; screening of crystallization conditions requires complete and rapid mixing, which means small droplets $(1<\mathrm{L} / \mathrm{W}<2)$. Note that droplets smaller than the tubing inner diameter $(\mathrm{L} / \mathrm{W}<1)$ are mobile in the tubing and risk coalescing.

Another crucial factor is droplet frequency fo (number of droplets per $\mathrm{s}^{-1}$ ). Relatively low $f_{D}$ is required to reduce droplet coalescence and contamination when there is precipitation. However, high-throughput gradient screening and optimization trials involve the formation of a large number of droplets in long tubing, with high values of $f$ (number of droplets per $\mathrm{cm}$ ). This is very challenging because droplets are unstable and tend to collapse while circulating in long tubing, due to the non-negligible hydraulic resistance.

In a T-junction, important parameters for droplets generation include the flow-rates of continuous and dispersed flows represented respectively by their mean velocities VD and $v_{c}$, the continuous flow viscosity $\mu_{c}$ and the interface tension between dispersed and continuous flows $\gamma_{C D}$. We take into account these flow properties by using the capillary number $\mathrm{Ca}\left(\mathrm{Ca}=\frac{\mu_{C} \times v_{C}}{\gamma_{C D}}\right)$. In addition, we identify an important new parameter $\mathrm{VTOT}_{\text {T }}$ the sum of $\mathrm{V}_{\mathrm{D}}$ and $\mathrm{V}_{\mathrm{C}}$. Droplet generation is similar for similar values of $\mathrm{Ca}$, leading to different regimes: a steady regime with low risk of droplet coalescence for $\mathrm{Ca}<0.2$. By contrast, the regime observed at $\mathrm{Ca}>2$ leads to high mobility of droplets in the tubing and thus a risk of coalescence (49). Consequently, whatever the junction used, we first adjust the viscosity and the velocity of the continuous flow to maintain $\mathrm{Ca}<$ 
0.2. If $\mu \mathrm{c}$ is high, $\mathrm{vc}$ needs to be low leading to a large range of $\mathrm{VTOT}$ (according to $\mathrm{VD}$ ), to which $\mathrm{L} / \mathrm{W}$ and $\mathrm{fD}$ are tuned. This method efficiently generates droplets in a $\mathrm{T}$-junction but also in cross and multiport junctions (29), even with viscous media (23).

\section{III.2. A low-consumption chemical library}

In microfluidic systems, the chemical library, i.e. tubing containing different components for crystallization, is generally injected using the same number of syringes as of chemical components: a minimum filling volume roughly $100 \mu \mathrm{L}$ per syringe. However, since microfluidics consumes little material, droplet generation does not consume the entire volume in the syringes. Trivedi et al. (51) reduced the number of syringes by mixing all the components in one syringe and separating them with a chromatography column to generate droplets of each component. However, the components need to be soluble in the same solvent.

To reduce the consumption of material and use a wide range of solvents, the tubing can be filled directly, instead of using a syringe $(20,30)$. To do so, tubing of the selected length is first filled with the continuous flow (to avoid contaminating the solutions) and then refilled with the liquid of interest. Figure $4 a$ shows the protocol for filling tubing of $150 \mu \mathrm{m}$ inner diameter with plugs of many different aqueous solutions of red and yellow dyes. These are separated from each other by an oil spacer (as continuous flow) to prevent them from mixing. Successive refilling operations are shown in Figure 4b (30). Then the solutions are successively injected into the microfluidic system to form droplets (9). For instance, a length of $15 \mathrm{~cm}$ of $150 \mu \mathrm{m}$ ID tubing contains $\sim 2.7 \mu \mathrm{L}$, corresponding to about 900 droplets of $3 \mathrm{~nL}$. Consequently, using plugs instead of syringes considerably reduces the consumption of materials. The length of the plugs, and thus their volume, depends on the number of droplets required by the user. 


\section{III.3. Mixing components with the solution of interest}

To add one or several components to a liquid containing the solute in a droplet-based microfluidic system, flows are either mixed directly with the solute flow in a multiport junction, or injected into droplets generated from the solute. Mixing aqueous solutions (30) with high viscosity and/or low interfacial energy (32) is possible using operating parameters (see part III.1) and droplet concentration is verified with an on-line spectrophotometer.

In the case of organic solvent mixed with water in a cross-junction, droplets generated in a continuous flow (oil) quickly coalesce, especially since no surfactant is used to stabilize them. We suggest that this is due to the interfacial energy $\gamma_{C D}$, which is higher for the oil-water interface than for the oil-organic interface (30). Thus, mixing the aqueous solution and the organic solvent first creates an interfacial energy gradient with oil, between the organic solvent-rich areas and the water-rich areas (before homogenization). This variation of the interfacial energy probably leads to a Marangoni flow. The result is a disturbance in the movement of generated droplets, causing their coalescence, as previously shown in the case of the addition of a surfactant (52). Moreover, once the droplets are homogeneous, their interfacial energy with the tubing wall is much lower than for purely aqueous droplets. Hence droplets tend to wet the tubing wall, also promoting their coalescence. Consequently, it is impossible to add a pure organic solvent to water without disturbing the flow of generated droplets.

To reduce the effects of interfacial energy changes, we replaced the organic solvent by a mixture of organic solvent and water (30). Different proportions of water were tested with various organic solvents and the addition of water clearly improved the stability of the generated droplets. However, the proportion of water required for this stabilization varies from one organic solvent to another. This proportion is correlated 
to a threshold value of $\gamma_{\mathrm{CD}}$, in the range $15-20 \mathrm{~mJ}^{\mathrm{m}} \mathrm{m}^{-2}$, below which the droplets are not stable in the tubing. This value is very close to the critical surface energy of Teflon, $18 \mathrm{~mJ} \cdot \mathrm{m}^{-2}(30)$, which represents the maximum interfacial energy of a liquid that wets the surface. Since the surface (in FEP (fluorinated ethylene propylene)) of the tubing is chemically similar to that of Teflon, this confirms that the droplets become unstable and tend to coalesce when they wet the tubing wall.

\section{FUNDAMENTALS OF CRYSTALLIZATION-THE PHASE DIAGRAM}

Controlling the crystals and their properties usually strongly depends on the starting position in the phase diagram and the chemical composition. This requires a thorough understanding of the parameters of the phase diagram. For instance, the Microbatch ${ }^{\circledR}$ method is used to estimate the phase diagram of a protein according to crystallization agent concentration (53). This method is also used with droplet-based microfluidic systems to determine solubility curve, metastable zone, and nucleation kinetics (Figure 7) $(24,54)$.

\section{IV.1. The solubility curve}

In crystallization from solution, the first step consists in dissolving a chemical species in a solvent. When the concentration in the solution is greater than the solubility of the species in the solvent at the considered temperature, the solution is supersaturated and a solid phase can crystallize. Measuring the solubility curve is a crucial step in crystallization studies and process development. Therefore, all methods are based on measuring the concentration of a saturated solution. For instance, attenuated total reflection - Fourier transform infrared (ATR-FTIR) (55, 56) and Raman (57) spectroscopies were reported for in-situ solubility measurements. Raman 
spectroscopy was used by Laval et al. with a microfluidic setup for rapid screening of the solubility of an organic solute $(58,59)$. Moreover, as previously pointed out, microfluidic experiments involve dissolving large quantities of material in a given volume until saturation.

To reduce the quantity of material consumed, our answer is to generate saturated solutions directly from powder in the microfluidic tubing (Figure 5) (34). The solvent flows through a powder bed blocked by a filter. At the outlet of the filter, due to the molecule dissolving, the solution concentration is at saturation. To avoid calibration of absorbance, which consumes additional material, a dilution step is added (Figure 5a) and the diluted solution is analyzed by an on-line UV-Vis spectrometer (Figure 5b). The two columns and the $\mathrm{T}$-junction are placed in a temperature-controlled incubator, from room temperature to $65^{\circ} \mathrm{C}$ (Figure 5c) (23).

We applied this method to measure solubility in different solvents, using paracetamol as a model compound (34). In Figure 6a-c, we compared our results with measurements realized in large volumes by various techniques (60-66). Solubility data were consistent, showing the versatility, the reliability and the solubility range accessible with our technique. We also performed solubility measurements for glyclazide from TES (Figure 6d) (34). Data were consistent with measurements in large volumes (67). The very good reproducibility confirmed our method's accuracy in concentration and temperature. Thus, our device rapidly measures he entire solubility curve at a variety of temperatures ranging from 20 to $60^{\circ} \mathrm{C}$ using extremely small quantities of material (3-30mg), with a concentration range from $\mathrm{mg} / \mathrm{mL}$ to hundreds of $\mathrm{mg} / \mathrm{mL}$ 


\section{IV.2. Metastable zone and phases occurrence}

The metastable zone $(\mathrm{MZ})$ is the temperature range within which the supersaturated solution can remain for the required time without losing its metastability (68). Figure 7 shows that the minimum temperature (TMZ) defines two zones where nucleation and growth are kinetically or thermodynamically promoted, respectively. It must be noted that the nucleation corresponds to the appearance of crystals and growth to their subsequent expansion. Moreover, growth of crystals is optimal in the MZ, at low supersaturation, where nucleation is kinetically inactive. Crystal growers therefore aim to separate nucleation and growth phases.

As nucleation is a stochastic phenomenon, the probability of observing the first nuclei is very low, for spatial and temporal reasons. Nucleation can, however, be induced in the $M Z$, using external fields $(6,54,69)$ which enable the timing of the nucleation event to be controlled. Controlling where nucleation occurs is possible by confining the nucleation volume using small droplets in microfluidic systems. Moreover, confinement makes it possible to dissociate crystal nucleation from growth, allowing nucleation to be studied and controlled.

\section{IV.2.1. Measuring the metastable zone width}

In practice, TMZ, at which there is no crystal for a given concentration, needs to be determined. To do so, droplets are stored at different temperatures $T$ for the same time, long enough for the crystals to nucleate and grow, which depends on growth rate. During this time if $T<\mathrm{TMZ}$, crystals nucleate and if $T>\mathrm{TMZ}$, no crystals appear. For a given concentration, the TMZ, at which there is no crystals, is the corresponding temperature on the metastable zone limit MZL (Figure 7). We applied the method described in Figure 7 to measure the MZL for lysozyme in an aqueous solution (22) 
(Figure 7a) and for caffeine in ethanol (21) (Figure 7b). Determining the MZL is a key step in nucleation studies. In addition, the nucleation rate $\mathrm{J}$ can only be measured in the vicinity of this limit (69).

\section{IV.2.2. Polymorphs and phases in droplets}

Polymorphs are different solid phases for which the chemical composition is the same. Moreover, according to Ostwald's rule of states (70), a chemical system does not tend directly towards the most stable state, but rather tends towards the closest metastable state. Hence performing many spontaneous nucleation experiments increases the probability of observing an event. Thus, for statistical reasons, droplet-based microfluidics is adapted for detection of new phases. For instance, in our droplets of lysozyme, a sea urchin-like habit different from the tetragonal crystal generally observed appeared in 6 droplets out of 237 (22) (Figure 8a). Crystals with this urchinlike habit were previously observed $(71,72)$ but were not easy to isolate in $\mathrm{mL}$ crystallizers. In our droplets, increasing temperature to $30^{\circ} \mathrm{C}$ dissolved only the sea urchin-like habit (on the right in Figure $\mathbf{8 b}$ and $\mathbf{8 c}$ ), and not the tetragonal crystal. Thus, we concluded that crystals with a sea-urchin habit are a different phase (73). Moreover, because of mononuclear nucleation, the nucleated crystal of the metastable phase cannot easily follow a solution-mediated phase transition to a more stable phase. Small volumes of droplets seem to "freeze" the metastable phase (74). Lastly, the higher supersaturations reached in microfluidics, due to volume reduction, increase the probability of nucleating a metastable phase $(3,75)$.

In general, even with phases of different compositions, solvates for example, the same phenomena are observed. For instance, we observed in the case of rasburicase that the same experimental conditions produced different crystal habits and phases. 
Moreover, the two polymorphs known for rasburicase (76) appeared simultaneously in droplets (Figure 9) (23). The main reason for this concomitant nucleation is that the difference between their solubilities is weak.

\section{IV.3. Nucleation kinetics}

The nucleation rate $J$ is the number of crystals that form in the supersaturated solution per unit of volume and per unit of time. To determine $J$, the Double Pulse Technique (DPT) enables nucleation and growth to be separated $(69,77,78)$. The value of $J$ at a given concentration $C$, is given by the variation of the number of crystals nucleated, with nucleation time. Therefore, DPT imposes a sequence of temperatures using $T_{\text {growth }}$

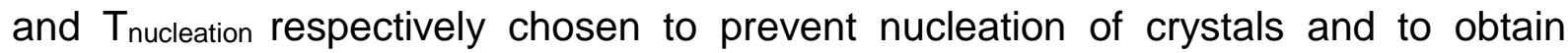
nucleation of crystals (Figure 7). The solubility curve and MZ are used to choose $T_{\text {nucleation }}$ to $\mathrm{T}_{\text {growth. }}$ For instance, for lysozyme (33), $\mathrm{T}_{\text {Nucleation }}$ of $20^{\circ} \mathrm{C}$ enabled us to compare our data with the data from the literature $(78,79)$. TGrowth of $40^{\circ} \mathrm{C}$ was chosen because it is in the MZ (Figure 7a). We chose nucleation times under $2 \mathrm{~h}$ to guarantee that lysozyme concentration was constant in the droplets: after $2 \mathrm{~h}$, the growth of nuclei depletes the droplet concentration (33).

The average number of crystals nucleated per droplet varied linearly with time, confirming steady-state nucleation (Figure 10a). The steady-state nucleation rate was thus determined by the slope (Figure 10b). Moreover, straight lines passed through the axis origins except for the highest supersaturation (33), indicating that the data were not affected by major heterogeneous nucleation (78). As shown in Figure 10b, our kinetic data are in good agreement with the data of Galkin and Vekilov $(5,78)$ obtained for the same composition of Lysozyme solution at $12.6^{\circ} \mathrm{C}$, using larger droplets $(1 \mu \mathrm{L})$ suspended in Teflon wells. Moreover, the supersaturation range 
experimentally accessible when the volume of nucleation is reduced to the $\mathrm{nL}-\mathrm{pL}$ range is increased for kinetic $(24)$ and thermodynamic $(80,81)$ reasons.

When crystals appear in droplets containing no crystals of that phase, the nucleation is called "primary nucleation" and $\mathrm{J}$ is determined by the Classical Nucleation Theory (CNT) derived from the Gibbs treatment of droplet nucleation (82). Then surface interactions are taken into account by introducing an effective interfacial energy $\gamma_{\text {ef }}$ of the interface between the solution and the critical nucleus. $J$ is given by the equation: $J=K_{0}\left(\frac{16 \pi}{3} \frac{\Omega^{2} \gamma_{e f}^{3}}{(k T)^{3} \ln ^{2} \beta}\right)(\mathbf{2 2}, 31)$, where $K_{0}$ is a pre-exponential factor, $\Omega$ is the volume of a molecule inside the crystal, $k$ is the Boltzmann constant, $T$ is the temperature and $\beta$ is the supersaturation, $(\beta=C / C s$ where $C$ is the solution concentration and $C s$ is the solubility). In the lysozyme case, our values of $J$ varied exponentially with $\left(-1 / \ln { }^{2} \beta\right)$, consistent with this equation, and the parameter $\gamma_{\mathrm{ef}}$ showed that primary nucleation was not influenced by the container material (33). In fact, the continuous flow in microfluidic systems creates a "containerless" environment, as pointed out by Chayen (83). However, the $\gamma_{\mathrm{ef}}$ we determined in different continuous flows (fluorinated oil and in silicon oil) demonstrated the influence of the droplet-oil interface in droplet-based microfluidics (31).

\section{SCREENING AND OPTIMIZATION OF CRYSTALLIZATION CONDITIONS}

Screening and optimizing crystallization conditions of a solute consist in evaluating methods, reagents, and other chemical and physical variables with the objective of producing crystals and/or identifying the variables which are positively or negatively associated with crystallization of the solute. With proteins, a large number of crystallization reagents (buffers, crystallization agents, polymers) are first tested to identify the appropriate combinations of reagents that produce the desired crystal 
phase. Then, the optimization finely screens concentrations of each reagent in the combination to grow crystals of desired size and quality. For instance, production of large crystals of high quality is crucial in the determination of protein structures by $\mathrm{X}$ ray diffraction $(X R D)$.

\section{V.1. Screening of protein crystallization conditions}

To screen one or several components in a droplet-based microfluidic system, the flows of components can be mixed directly with the solute flow in a multiport junction $(29,51$, $84,85)$ yielding droplets of the mixture. However, the change of scale in microfluidic systems influences nucleation kinetics: the smaller the volume the longer the induction time, all things being equal. Thus, the "scale-down" requires generation of higher supersaturation in the droplets, which can lead to precipitation, notably at interfaces created in non-homogeneous droplets $(50,84,85)$. Then, precipitates tend to adhere to the walls of the channels and perturb or even obstruct the flow, with the risk of clogging the channel, one of the major drawbacks in microfluidics $(86,87)$. To avoid clogging and ensure higher supersaturation, several microfluidic junctions can be mounted together to successively add reagents to droplets and ensure homogeneity (see part III.3) $(30,51)$. Moreover, by increasing the number of inlets, the concentration of each component can be screened.

For instance, a cross-junction is used to mix a protein and a buffer and a T-junction is used to inject a crystallization agent or a ligand for co-crystallization. As the solutions injected into the cross and the T- junctions are miscible, the third solution can be added inside the pre-existing droplets (51). 


\section{V.1.1. Screening crystallization agents}

Here, we show an example with different crystallization agents of lysozyme prepared in a tubing as a "chemical library" and screened in droplets using a T-junction( Figure 11) (30). The respective flow rates of lysozyme and of "chemical library" were varied so as to keep the size and frequency of droplets constant. Whatever the flow-rate, the two solutions mixed well with the droplets passing through the T-junction, without creating a new interface and thus a new droplet. Moreover, at constant flows, the droplets at the outlet of the T-junction were homogeneous both in size and frequency. Here, applying our screening strategy to lysozyme led us to select $\mathrm{NaCl}$ as crystallization agent to obtain the tetragonal phase (Figure 11c). Thus, this crystallization condition was used for size optimization using the fine-gradient method (29) (see part V.2.2.).

\section{V.1.2. Screening ligand for co-crystallization}

In pharmaceutical research, the co-crystallization of a target protein with many different ligands often enables the identification and design of new active pharmaceutical ingredients. This process is called structure-based drug design (88). To perform protein-ligand co-crystallization, the protein and the ligand have to be incubated together before supersaturation is generated. First, protein and ligands are mixed in a cross-junction, and second, the crystallization agent is introduced into a T-junction. The length of the tubing between the cross- and the T-junctions is chosen according to ligand-protein binding affinity (the lower the binding affinity, the longer the tubing). Ligands are usually only soluble in organic solvents whereas proteins are soluble in aqueous buffers. Thus, mixing ligand and protein solutions requires mixing two different phases during droplet generation. As seen in part III.3., the ligand has to be 
dissolved in a mixture of organic solvent and water, which improves the stability of the generated droplet (30).

For instance, for Human quinone reductase 2 (QR2) co-crystallization experiments, we used a known ligand of this protein, melatonin solubilized in DMSO. As the concentration of melatonin required was low $(<\mathrm{few} m \mathrm{~m})$, it was solubilized by the mixture DMSO and water. Moreover, as proteins are not soluble in organic solvent, the final droplets had to contain no more than $10 \%$ organic solvent (89) to avoid disturbing their three-dimensional structure and compromising crystal quality. Thus, adding water to the ligand solutions also reduced the final amount of DMSO in the crystallization droplets, decreasing the risk of protein denaturation.

To validate our microfluidic platform for ligand screening applications, we realized a co-crystallization experiment of QR2 with melatonin in 3 steps (30): First, a 40\% DMSO solution with water (without melatonin) was mixed with the protein solution in the crossjunction. The resulting droplets were then mixed with an aqueous solution of crystallization agent in the $\mathrm{T}$-junction so that the final droplets contained $8 \% \mathrm{DMSO}$. The crystals grown in these conditions (Figure 12a) were similar to those obtained in pure aqueous solution (Figure 12b) (32), confirming that DMSO concentration was low enough to preserve the protein structure and its crystallization. Then, QR2 was cocrystallized with melatonin in the $40 \%$ DMSO solution leading to crystals (Figure 12c). For ligand screening applications, the tubing containing melatonin simply needs to be filled with a "library" of ligands, as in Figure 4.

\section{V.2. Optimizing crystallization conditions}

After selecting a range of reagents through the screening step, optimization proceeds by imposing fine gradients of the concentration of one or several of these reagents. 
The optimization of crystallization conditions becomes challenging if viscous precipitants and/or detergents are used.

\section{V.2.1. Optimization in non-viscous solutions}

As a simple example, we optimized lysozyme crystallization by varying its concentration in a given buffer. The crystallization conditions were optimized using the fine-gradient method (29): according to screening results (part V.1.1), $\mathrm{NaCl}$ buffer and lysozyme solution were injected into a cross-junction face to face (Figure 13). The concentration of lysozyme increased with the ratio of the flow rates (lysozyme/ $\mathrm{NaCl}$ ). Moreover, the respective flow rates were chosen so as to obtain $1 \leq \mathrm{L} / \mathrm{W} \leq 2$ (as seen in part III.1), ensuring droplet homogeneity. A wide range of supersaturation was scanned and we obtained large single crystals of protein (Figure 13a-c) (30).

The fine-gradient method also enables the phase diagram (part IV) to be determined according to the concentration of a crystallization agent. In the case of QR2, we first determined the phase diagram using large volumes according to the concentration of sulfate ammonium. As seen in part IV, Figure 14 (left) shows the solubility curve, the metastable zone and the precipitation zone, where we tested conditions. Figure 14 (right) shows 5 representative droplets out of 60 droplets of $2 \mathrm{nl}$ generated in each condition, confirming the phase diagram. Moreover, fine-gradient optimization was used to choose the crystals in Figure 14 for X-ray diffraction (XRD) (32).

\section{V.2.2. Optimization in viscous solution}

We explored crystallization in a viscous medium with rasburicase, a biomolecule which crystallizes in polyethylene glycol (PEG) solution, a viscous media (23). For high concentrations of rasburicase, the addition of a high percentage of PEG led to 
precipitation at droplet formation. Then, precipitation led to crystals by the Ostwald ripening mechanism (Figure 15a) (23). For low concentrations of rasburicase and PEG, no precipitates appeared and nucleation occurred after a few hours, leading to a single crystal (Figure 15b). Other conditions are shown in Figure 9 with dispersed numbers of crystals and/or phases (23).

\section{V.2.3 Optimization in low interfacial energy solution}

For membrane proteins, in addition to PEG as a precipitant, detergents are required to solubilize proteins in water, like $\mathrm{C}_{10} \mathrm{E}_{5}$ (Pentaethylene Glycol Monodecyl Ether). For instance, lysozyme was used as model protein (not as complex as membrane proteins) to demonstrate the handling of viscous and low interfacial energy solutions (29). To mix these three solutions and generating droplets with a fourth continuous flow, a multiport junction had to be used. Since all droplets were generated using the hydrodynamic operating method (see part III.1) they had identical sizes, frequencies, spacing, etc. Consequently, varying only one ingredient in the same volume of crystallization solution led to comparable and precise mapping in the crystal phase diagram. The parameter which was varied was the concentration of lysozyme. A 5step concentration gradient of lysozyme $(5-15 \mathrm{mg} / \mathrm{mL})$ was set by keeping the concentration of $\mathrm{PEG}$ and $\mathrm{C}_{10} \mathrm{E}_{5}$ constant. The concentration of lysozyme within droplets was verified using online recording of absorbance at 280nm. Almost 200 droplets were generated in tubing of $2 \mathrm{~m}$ approximate length. The whole droplet trial took less than $1 \mathrm{~h}$, consuming only $50 \mu \mathrm{L}$ of lysozyme substrate solution. Droplet incubation and in-situ observation were completed after $24 \mathrm{~h}$ of incubation at $20^{\circ} \mathrm{C}$. We carefully determined the crystal morphogram and mapped the transition from mono- to multi-nucleation of crystals for increasing protein concentrations (Figure 16). For 
instance, mono-nucleation led to the growth of large single crystals $(>50 \mu \mathrm{m})$ (insert in Figure 16 A1, A2 and A3). These optimized conditions could be scaled up to obtain larger crystals for structure determination in X-ray diffraction.

\section{V.3. X-ray diffraction of crystals in droplets}

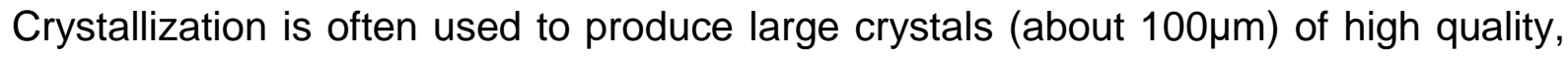
required to determine the nature of the three-dimensional structure of proteins by $\mathrm{X}$ ray diffraction $(\mathrm{XRD})$, allowing a better understanding of their biological functions. However, manual handling of the sample crystals can mechanically and environmentally stress them. The stress induced during this delicate step may affect the quality of the crystal and decrease its diffractive power. To minimize manual handling, an alternative is in-situ X-ray data collection. One approach involves using X-ray-transparent microfluidic devices (90-99). Another solution, following the pioneering work of Yadav et al. (100), is to collect X-ray data directly in a micro-capillary $(9,101)$. For ex-situ data collection, Gerdts et al. (102) and Stojanoff et al. (92) harvested a protein crystal from a microfluidic channel using a cryo-loop and Li et al. (9) made crystals flow out of a capillary and then looped and flash-cooled them. Two approaches can be used: in-situ XRD of droplets in tubing or ex-situ XRD by depositing crystals on a MicroMesh, for analysis by XRD on the PROXIMA-1 beamline at Synchrotron SOLEIL.

\section{V.3.1. In-situ XRD}

In droplet-based microfluidic systems, droplets are easily generated and stabilized in Teflon tubing due to the non-wettability of Teflon with many solutions (aqueous and mixed aqueous and organic) and to its wettability with the continuous flow (oil). Crystals 
thus nucleate in droplets stored in Teflon tubing. However, Teflon-related background noise is significant in the diffraction patterns. This reduces the quality of the diffraction data (100) and strongly reduces the observed diffraction limits of the crystals. Therefore, we transferred droplets containing the crystals of interest from tubing in Teflon to tubing in silica for in-situ XRD without cooling.

In the case of QR2 crystals obtained after screening and optimizing crystallization conditions (see part V.2.1.), we transferred the droplets from experiment (Figure 14b) to silica tubing. The internal silica tubing wall was coated with a commercial hydrophobic surface-coating agent to ensure droplet stability. The silica tubing containing the droplets was directly mounted on a magnetic base extracted from standard SPINE sample loops, ready for transfer to the X-ray setup (Figure 17a). A crystal of Figure 14b analyzed by XRD at room temperature gave diffraction to a resolution of $2,7 \AA$ (32), enabling the space group of the crystal to be determined. It was in accordance with space groups reported in the literature (103), regardless of whether we used cryogenic conditions or not.

\section{V.3.2. Ex-situ XRD}

As crystals of QR2 were stored in droplets in Teflon tubing (Figure 14b), they were deposited on a MicroMesh using a high-precision micro-injector for flow control and micromanipulators for precise displacement in $X, Y$ and $Z$ (104). The crystals were placed singly on the MicroMesh (Figure 17b), which was immediately extracted from the oil bath and immersed in liquid nitrogen to cryogenize the crystals. For cryoprotection, either the oil acted as a cryo-protectant, or crystals were immersed in a drop of glycerol. Thus, the crystals were extracted without direct handling or mechanical stress and prepared for diffraction studies under cryogenic conditions. 
Their analysis by XRD with or without glycerol gave diffraction to a resolution of $2,3 \AA$ (32).

Finally, the crystals obtained after screening and optimization of crystallization conditions were characterized by both in-situ and ex-situ X-ray diffraction. A complete data set was obtained from several crystals of high quality, due to strong X-ray damage to crystals, notably at room temperature. Nevertheless, as microfluidics yields hundreds to thousands of droplets with identical composition, serial crystallography at room temperature would yield a complete set of data for structural resolution with limited noticeable effects from radiation damage (97).

\section{CONCLUSION}

This review compares droplet-based microfluidic systems used to study biomolecule crystallization fundamentals, such as the phase diagram: solubility curve, nucleation, polymorphism and phases. As an alternative to these systems, an original highthroughput droplet-based microfluidic platform is presented. It is composed of commercially available modules in independent units for directly solubilizing powder, mixing various media, controlling droplet size, frequency and concentration and, incubating and observing hundreds of identical droplets at different temperatures. It is compatible with all solvents without the need for surfactant. Its flexibility permits phase diagram determination and crystallization studies (screening and optimizing experiments), and makes it easy to use for non-specialists in microfluidics. Moreover, it allows concentration measurement via UV spectroscopy and solid characterization via XRD analysis. Given the stochasticity of nucleation, it allows a large number of experiments per condition. Using $\mathrm{nL}$ droplets, generating a "chemical library" and directly solubilizing powder mean that the platform economizes both material and time. 
ACKNOWLEDGMENTS: We thank Technologie Servier and Institut de Recherche Servier for financial support. We are grateful to T. Bactivelane (CINaM) and M. Audiffren (ANACRISMAT) for technical assistance. We thank Marjorie Sweetko for English revision.

\section{LITERATURE CITED}

1. Veesler S, Puel F. 2015. Crystallization of Pharmaceutical Crystals. In Handbook of Crystal Growth (Second Edition), ed. T Nishinaga, pp. 915-49. Boston: Elsevier

2. Candoni N., Grossier R., Hammadi Z., Morin R., Veesler S. 2012. Practical Physics Behind Growing Crystals of Biological Macromolecules Protein \& Peptide Letters 19: 714-24

3. Mangin D, Puel F, Veesler S. 2009. Polymorphism in Processes of Crystallization in Solution: A Practical Review. Organic Process Research \& Development 13: 1241-53

4. Kashchiev D. 2000. Nucleation : basic theory with applications. Oxford: ButterworthHeinemann. 529 pp.

5. GALKIN O., VEKILOV P.G. 2000. Are nucleation kinetics of protein crystals similar to those of liquid droplets? J. Am. Chem. Soc. 122: 156-63

6. Hammadi Z, Grossier R, Zhang S, Ikni A, Candoni N, et al. 2015. Localizing and inducing primary nucleation. Faraday Discussions 179: 489-501

7. Jiang S, ter Horst JH. 2011. Crystal Nucleation Rates from Probability Distributions of Induction Times. Crystal Growth \& Design 11: 256-61

8. Svärd M, Nordström FL, Jasnobulka T, Rasmuson ÅC. 2009. Thermodynamics and Nucleation Kinetics of m-Aminobenzoic Acid Polymorphs. Crystal Growth \& Design 10: 195-204

9. Li L, Mustafi D, Fu Q, Tereshko V, Chen DL, et al. 2006. Nanoliter microfluidic hybrid method for simultaneous screening and optimization validated with crystallization of membrane proteins. Proceedings of the National Academy of Sciences 103: 19243-48

10. Shim J-u, Cristobal G, Link DR, Thorsen T, Fraden S. 2007. Using Microfluidics to Decouple Nucleation and Growth of Protein. Crystal Growth \& Design 7: 2192-94

11. Squires TM, Quake SR. 2005. Microfluidics: Fluid physics at the nanoliter scale. Reviews of Modern Physics 77: 977

12. Dombrowski RD, Litster JD, Wagner NJ, He Y. 2007. Crystallization of alpha-lactose monohydrate in a drop-based microfluidic crystallizer. Chemical Engineering Science 62: 4802-10

13. Hansen CL, Skordalakes E, Berger JM, Quake SR. 2002. A robust and scalable microfluidic metering method that allows protein crystal growth by free interface diffusion. Proceedings of the National Academy of Sciences 99: 16531-36

14. Perry SL, Guha S, Pawate AS, Bhaskarla A, Agarwal V, et al. 2013. A microfluidic approach for protein structure determination at room temperature via on-chip anomalous diffraction. $L a b$ on a Chip 13: 3183-87

15. Dhouib K, Malek CK, Pfleging W, Gauthier-Manuel B, Duffait R, et al. 2009. Microfluidic chips for the crystallization of biomacromolecules by counter-diffusion and on-chip crystal X-ray analysis. Lab on a Chip 9: 1412-21

16. Otálora F, Gavira JA, Ng JD, García-Ruiz JM. 2009. Counterdiffusion methods applied to protein crystallization. Progress in Biophysics and Molecular Biology 101: 26-37

17. Li L, Ismagilov RF. 2010. Protein crystallization using microfluidic technologies based on valves, droplets, and SlipChip. Annu Rev Biophys 39: 139-58

18. Zheng B, Gerdts CJ, Ismagilov RF. 2005. Using nanoliter plugs in microfluidics to facilitate and understand protein crystallization. Current Opinion in Structural Biology 15: 548-55 
19. Li L, Mustafi D, Fu Q, Tereshko V, Chen DL, et al. 2006. Nanoliter microfluidic hybrid method for simultaneous screening and optimization validated with crystallization of membrane proteins. Proc Natl Acad Sci U S A 103: 19243-8

20. Gerdts CJ, Elliott M, Lovell S, Mixon MB, Napuli AJ, et al. 2008. The plug-based nanovolume Microcapillary Protein Crystallization System (MPCS). Acta Crystallographica Section D 64: 1116-22

21. Ildefonso M, Candoni N, Veesler S. 2012. A Cheap, Easy Microfluidic Crystallization Device Ensuring Universal Solvent Compatibility. Organic Process Research and Development 16: $556-60$

22. Ildefonso M., Revalor E., Punniam P., Salmon J.B., Candoni N., Veesler S. 2012. Nucleation and polymorphism explored via an easy-to-use microfluidic tool. Journal of Crystal Growth 342: 9-12

23. Zhang S, Ferté N, Candoni N, Veesler S. 2015. Versatile Microfluidic Approach to Crystallization. Organic Process Research \& Development 19: 1837-41

24. Candoni N, Hammadi Z, Grossier R, Ildefonso M, Morin R, Veesler S. 2015. Addressing the stochasticity of nucleation: Practical approaches. In Advances in Organic Crystal Chemistry, ed. MM Rui Tamura, pp. 95-113: Springer

25. Whitesides GM. 2006. The origins and the future of microfluidics. Nature 442: 368-73

26. Beebe DJ, Moore JS, Bauer JM, Yu Q, Liu RH, et al. 2000. Functional hydrogel structures for autonomous flow control inside microfluidic channels. Nature 404: 588-90

27. Unger MA, Chou H-P, Thorsen T, Scherer A, Quake SR. 2000. Monolithic Microfabricated Valves and Pumps by Multilayer Soft Lithography. Science 288: 113-16

28. McDonald JC, Whitesides GM. 2002. Poly(dimethylsiloxane) as a Material for Fabricating Microfluidic Devices. Accounts of Chemical Research 35: 491-99

29. Zhang S, Gerard CJJ, Ikni A, Ferry G, Vuillard LM, et al. 2017. Microfluidic platform for optimization of crystallization conditions. Journal of Crystal Growth 472: 18-28

30. Gerard CJJ, Ferry G, Vuillard LM, Boutin JA, Ferte N, et al. 2018. A Chemical Library to Screen Protein and Protein-Ligand Crystallization Using a Versatile Microfluidic Platform. Crystal Growth \& Design 18: 5130-37

31. Ildefonso M, Candoni N, Veesler S. 2013. Heterogeneous nucleation in droplet-based nucleation measurements. Crystal Growth \& Design 13: 2107-10

32. Gerard CJJ, Ferry G, Vuillard LM, Boutin JA, Chavas LMG, et al. 2017. Crystallization via tubing microfluidics permits both in situ and ex situ X-ray diffraction. Acta Crystallographica Section F 73: 574-78

33. Ildefonso M., Candoni N., Veesler S. 2011. Using microfluidics for fast, accurate measurement of lysozyme nucleation kinetics. Cryst. Growth Des. 11: 1527-30

34. Peybernès $G$, Grossier $R$, A, Villard $F$, Letellier $P$, Lagaize $M$, et al. 2018. Microfluidics setup rapidly measures solubility directly from powder.

35. Garstecki P, Fuerstman MJ, Stone HA, Whitesides GM. 2006. Formation of droplets and bubbles in a microfluidic T-junction-scaling and mechanism of break-up. Lab on a Chip 6: 43746

36. Xu JH, Li SW, Tan J, Luo GS. 2008. Correlations of droplet formation in T-junction microfluidic devices: from squeezing to dripping. Microfluidics and Nanofluidics 5: 711-17

37. Christopher GF, Noharuddin NN, Taylor JA, Anna SL. 2008. Experimental observations of the squeezing-to-dripping transition in T-shaped microfluidic junctions. Physical Review E 78: 036317

38. Liu H, Zhang Y. 2009. Droplet formation in a T-shaped microfluidic junction. Journal of Applied Physics 106: -

39. Gupta A, Kumar R. 2010. Flow regime transition at high capillary numbers in a microfluidic Tjunction: Viscosity contrast and geometry effect. Physics of Fluids (1994-present) 22: - 
40. Glawdel T, Elbuken C, Ren CL. 2012. Droplet formation in microfluidic T-junction generators operating in the transitional regime. I. Experimental observations. Physical Review E 85: 016322

41. Glawdel T, Elbuken C, Ren CL. 2012. Droplet formation in microfluidic T-junction generators operating in the transitional regime. II. Modeling. Physical Review E 85: 016323

42. Wehking J, Gabany M, Chew L, Kumar R. 2013. Effects of viscosity, interfacial tension, and flow geometry on droplet formation in a microfluidic T-junction. Microfluidics and Nanofluidics: 1-13

43. Thorsen T, Roberts RW, Arnold FH, Quake SR. 2001. Dynamic Pattern Formation in a VesicleGenerating Microfluidic Device. Physical Review Letters 86: 4163-66

44. van Steijn V, Kleijn CR, Kreutzer MT. 2010. Predictive model for the size of bubbles and droplets created in microfluidic T-junctions. Lab on a Chip 10: 2513-18

45. Garstecki P, Stone HA, Whitesides GM. 2005. Mechanism for Flow-Rate Controlled Breakup in Confined Geometries: A Route to Monodisperse Emulsions. Physical Review Letters 94: 164501

46. Tice JD, Song H, Lyon AD, Ismagilov RF. 2003. Formation of Droplets and Mixing in Multiphase Microfluidics at Low Values of the Reynolds and the Capillary Numbers. Langmuir 19: 912733

47. Zhao C-X, Middelberg APJ. 2011. Two-phase microfluidic flows. Chemical Engineering Science 66: $1394-411$

48. Chen N, Wu J, Jiang H, Dong L. 2011. CFD Simulation of Droplet Formation in a Wide-Type Microfluidic T-Junction. Journal of Dispersion Science and Technology 33: 1635-41

49. Zhang S, Guivier-Curien C, Veesler S, Candoni N. 2015. Prediction of sizes and frequencies of nanoliter-sized droplets in cylindrical T-junction microfluidics. Chemical Engineering Science 138: 128-39

50. Song H, Bringer MR, Tice JD, Gerdts CJ, Ismagilov RF. 2003. Experimental test of scaling of mixing by chaotic advection in droplets moving through microfluidic channels. Applied Physics Letters 83: 4664-66

51. Trivedi V, Doshi A, Kurup GK, Ereifej E, Vandevord PJ, Basu AS. 2010. A modular approach for the generation, storage, mixing, and detection of droplet libraries for high throughput screening. Lab on a Chip 10: 2433-42

52. Baroud CN, Gallaire F, Dangla R. 2010. Dynamics of microfluidic droplets. Lab on a Chip 10: 2032-45

53. Chayen NE, Shaw Stewart PD, Maeder DL, Blow DM. 1990. An automated system for microbatch protein crystallization and screening. Journal of Applied Crystallography 23: 297-302

54. Candoni N., Hammadi Z., Grossier R., Ildefonso M., Revalor E., et al. 2012. Nanotechnologies dedicated to nucleation control. Int. J. Nanotechnol 9: 439-59

55. Dunuwila DD, Berglund KA. 1997. ATR FTIR spectroscopy for in situ measurement of supersaturation. Journal of Crystal Growth 179: 185-93

56. Lewiner F., KLEIN J.P., Puel F., Févotte G. 2001. On-line ATR FTIR measurement of supersaturation during solution crystallization processes. Calibration and applications on three solute/solvent systems. Chem. Engineering Science 56: 2069-84

57. Schwartz A.M., Berglund K.A. 1999. The use of Raman spectroscopy for in situ monitoring of lysozyme concentration during crystallization in a hanging drop. J. Crystal Growth 203: 599603

58. Laval P., Lisai N., Salmon J.B., Joanicot M. 2007. A microfluidic device based on droplet storage for screening solubility diagrams. Lab on a Chip 7: 829-34

59. Leng J., Salmon J.B. 2009. Microfluidic crystallization. Lab on a Chip 9: 24-34

60. Bustamante P, Romero S, Peña A, Escalera B, Reillo A. 1998. Enthalpy-entropy compensation for the solubility of drugs in solvent mixtures: Paracetamol, acetanilide, and nalidixic acid in dioxane-water. Journal of Pharmaceutical Sciences 87: 1590-96 
61. Hojjati H, Rohani S. 2006. Measurement and Prediction of Solubility of Paracetamol in Water-Isopropanol Solution. Part 1. Measurement and Data Analysis. Organic Process Research \& Development 10: 1101-09

62. Granberg RA, Rasmuson ÅC. 1999. Solubility of Paracetamol in Pure Solvents. Journal of Chemical \& Engineering Data 44: 1391-95

63. Nagai T, Prakongpan S. 1984. Solubility of Acetaminophen in Cosolvents. CHEMICAL \& PHARMACEUTICAL BULLETIN 32: 340-43

64. BUSTAMANTE P, ROMERO S, REILLO A. 1995. Thermodynamics of Paracetamol in Amphiprotic and Amphiprotic-aprotic Solvent Mixtures. Pharmaceutical Sciences 1: 505-07

65. Jouyban A, Chan H-K, Chew NYK, Khoubnasabjafari M, Acree JWE. 2006. Solubility Prediction of Paracetamol in Binary and Ternary Solvent Mixtures Using Jouyban\&ndash;Acree Model. Chemical and Pharmaceutical Bulletin 54: 428-31

66. Jiménez JA, Martínez F. 2006. Thermodynamic Study of the Solubility of Acetaminophen in Propylene Glycol + Water Cosolvent Mixtures. Journal of the Brazilian Chemical Society 17: 125-34

67. Detoisien T, Forite M, Taulelle P, Teston J, Colson D, et al. 2009. A Rapid Method for Screening Crystallization Conditions and Phases of an Active Pharmaceutical Ingredient. Organic Process Research \& Development 13: 1338-42

68. Kashchiev D., Verdoes D., Van Rosmalen G.M. 1991. Induction time and metastability limit in new phase formation. J. Crystal Growth 110: 373-80

69. Revalor E., Hammadi Z., Astier J. P., Grossier R., Garcia E., et al. 2010. Usual and Unusual Crystallization from Solution. J. Crystal Growth 312: 939-46

70. Ostwald W. 1897. Studien uber die bildung und umwandlund fester korper. Z. Phys. Chem. 22: $289-330$

71. ATAKA M, ASAI M. 1988. Systematic studies on the crystallization of lysozyme. J. Crystal Growth, 90: 86-93

72. Legrand L., Ries-Kautt M., Robert M.-C. 2002. Two polymorphs of lysozyme nitrate: temperature dependence of their solubility. Acta Crystallographica Section D 58: 1564-67

73. ASTIER J. P., VEESLER S. 2008. Using temperature to crystallize proteins: a mini-review. Cryst. Growth Des. 8: 4215-19

74. Lee AY, Lee IS, Myerson AS. 2006. Factors Affecting the Polymorphic Outcome of Glycine Crystals Constrained on Patterned Substrates. Chemical Engineering \& Technology 29: 281-85

75. Laval P, Giroux C, Leng J, Salmon J-B. 2008. Microfluidic screening of potassium nitrate polymorphism. Journal of Crystal Growth 310: 3121-24

76. Vivares D., Veesler S., Astier J.P., Bonneté F. 2006. Polymorphism of Urate oxidase in PEG solutions. Crystal Growth \& Design 6: 287-92

77. Tsekova D, Dimitrova S, Nanev CN. 1999. Heterogeneous nucleation (and adhesion) of Iysozyme crystals. Journal of Crystal Growth 196: 226-33

78. GALKIN O., VEKILOV P.G. 1999. Direct determination of the nucleation rates of protein crystals. J. Phys. Chem. B, 103: 10965-71

79. Selimovic S, Jia Y, Fraden S. 2009. Measuring the Nucleation Rate of Lysozyme using Microfluidics. Crystal Growth \& Design 9: 1806-10

80. Grossier R., Magnaldo A., veesler S. 2010. Ultra-fast crystallization due to Confinement. J. Crystal Growth 312: 487-89

81. Grossier R., Veesler S. 2009. Reaching one single and stable critical cluster through finite sized systems. Cryst. Growth Des. 9: 1917-22

82. Gibbs J. 1948. The Collected Works. Vol. 1. Thermodynamics: Yale University Press

83. Chayen NE. 1996. A novel technique for containerless protein crystallization. Protein Engineering 9: 927-29

84. Song H, Chen DL, Ismagilov RF. 2006. Reactions in Droplets in Microfluidic Channels. Angewandte Chemie International Edition 45: 7336-56 
85. Song H, Tice JD, Ismagilov RF. 2003. A Microfluidic System for Controlling Reaction Networks in Time. Angewandte Chemie International Edition 42: 768-72

86. Poe SL, Cummings MA, Haaf MP, McQuade DT. 2006. Solving the Clogging Problem: Precipitate-Forming Reactions in Flow. Angewandte Chemie International Edition 45: 1544-48

87. Zheng B, Roach LS, Ismagilov RF. 2003. Screening of Protein Crystallization Conditions on a Microfluidic Chip Using Nanoliter-Size Droplets. Journal of the American Chemical Society 125: 11170-71

88. Blundell TL, Jhoti H, Abell C. 2002. High-throughput crystallography for lead discovery in drug design. Nature Reviews Drug Discovery 1: 45-54

89. Mande SC, Sobhia ME. 2000. Structural characterization of protein-denaturant interactions: crystal structures of hen egg-white lysozyme in complex with DMSO and guanidinium chloride. Protein Engineering, Design and Selection 13: 133-41

90. Maeki M, Yamaguchi H, Tokeshi M, Miyazaki M. 2016. Microfluidic Approaches for Protein Crystal Structure Analysis. Analytical Sciences 32: 3-9

91. Dhouib K, Khan Malek C, Pfleging W, Gauthier-Manuel B, Duffait R, et al. 2009. Microfluidic chips for the crystallization of biomacromolecules by counter-diffusion and on-chip crystal Xray analysis. Lab on a Chip 9: 1412-21

92. Stojanoff V, Jakoncic J, Oren DA, Nagarajan V, Navarro Poulsen J-C, et al. 2011. From screen to structure with a harvestable microfluidic device. Acta Crystallographica Section F 67: 97175

93. Guha S, Perry SL, Pawate AS, Kenis PJA. 2012. Fabrication of X-ray compatible microfluidic platforms for protein crystallization. Sensors and Actuators B: Chemical 174: 1-9

94. Pinker F, Brun M, Morin P, Deman A-L, Chateaux J-F, et al. 2013. ChipX: A Novel Microfluidic Chip for Counter-Diffusion Crystallization of Biomolecules and in Situ Crystal Analysis at Room Temperature. Crystal Growth \& Design 13: 3333-40

95. Khvostichenko DS, Schieferstein JM, Pawate AS, Laible PD, Kenis PJA. 2014. X-ray Transparent Microfluidic Chip for Mesophase-Based Crystallization of Membrane Proteins and On-Chip Structure Determination. Crystal Growth \& Design

96. Horstman EM, Goyal S, Pawate A, Lee G, Zhang GGZ, et al. 2015. Crystallization Optimization of Pharmaceutical Solid Forms with X-ray Compatible Microfluidic Platforms. Crystal Growth \& Design

97. Heymann M, Opathalage A, Wierman JL, Akella S, Szebenyi DME, et al. 2015. Roomtemperature serial crystallography using a kinetically optimized microfluidic device for protein crystallization and on-chip X-ray diffraction. Corrigendum. IUCrJ 2: 601

98. Maeki M, Pawate AS, Yamashita K, Kawamoto M, Tokeshi M, et al. 2015. A Method of Cryoprotection for Protein Crystallography by Using a Microfluidic Chip and Its Application for in Situ X-ray Diffraction Measurements. Analytical Chemistry 87: 4194-200

99. Sui S, Perry SL. 2017. Microfluidics: From crystallization to serial time-resolved crystallography. Structural Dynamics 4: 032202

100. Yadav MK, Gerdts CJ, Sanishvili R, Smith WW, Roach LS, et al. 2005. In situ data collection and structure refinement from microcapillary protein crystallization. Journal of Applied Crystallography 38: 900-05

101. Maeki M, Yoshizuka S, Yamaguchi H, Kawamoto M, Yamashita K, et al. 2012. X-ray Diffraction of Protein Crystal Grown in a Nano-liter Scale Droplet in a Microchannel and Evaluation of Its Applicability. Analytical Sciences 28: 65-65

102. Gerdts CJ, Stahl GL, Napuli A, Staker B, Abendroth J, et al. 2010. Nanovolume optimization of protein crystal growth using the microcapillary protein crystallization system. Journal of Applied Crystallography 43: 1078-83

103. Foster CE, Bianchet MA, Talalay P, Zhao Q, Amzel LM. 1999. Crystal Structure of Human Quinone Reductase Type 2, a Metalloflavoprotein. Biochemistry 38: 9881-86

104. Grossier R., Hammadi Z., Morin R., Magnaldo A., veesler S. 2011. Generating nanoliter to femtoliter microdroplets with ease. Applied Physics Letters 98: 091916-3 


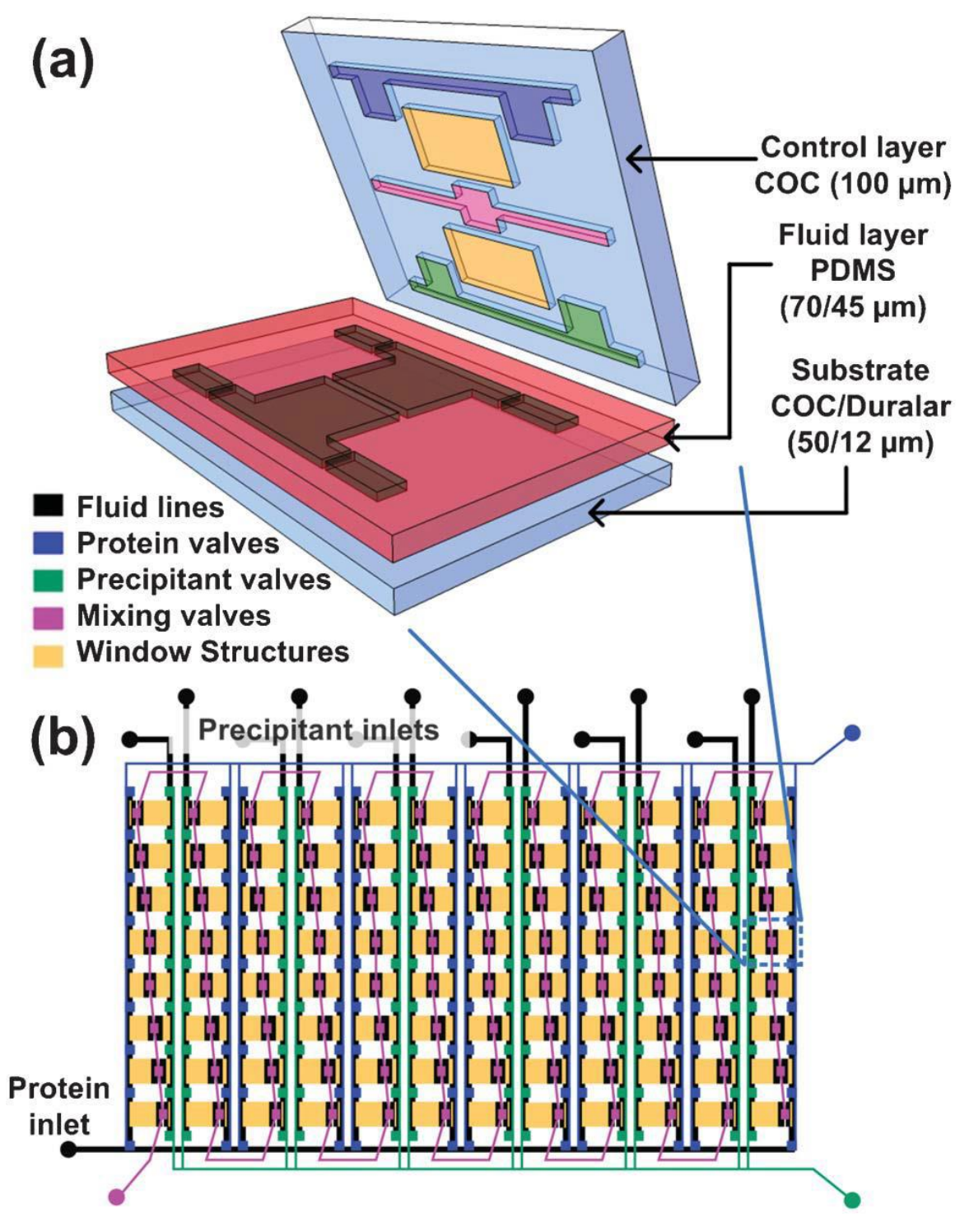

Figure 1. Droplets-based microfluidic chip with automated fluid handling: (a) 3D exploded view showing the different materials used for various layers of the hybrid device, in cyclic olefin copolymer (COC), polydimethylsiloxane (PDMS), and Duralar® (Graphix Arts). (b) Schematic design of the chip with 96 wells, valve lines for filling in different components, and protein and precipitant chambers. Reprinted with permission from (14). 


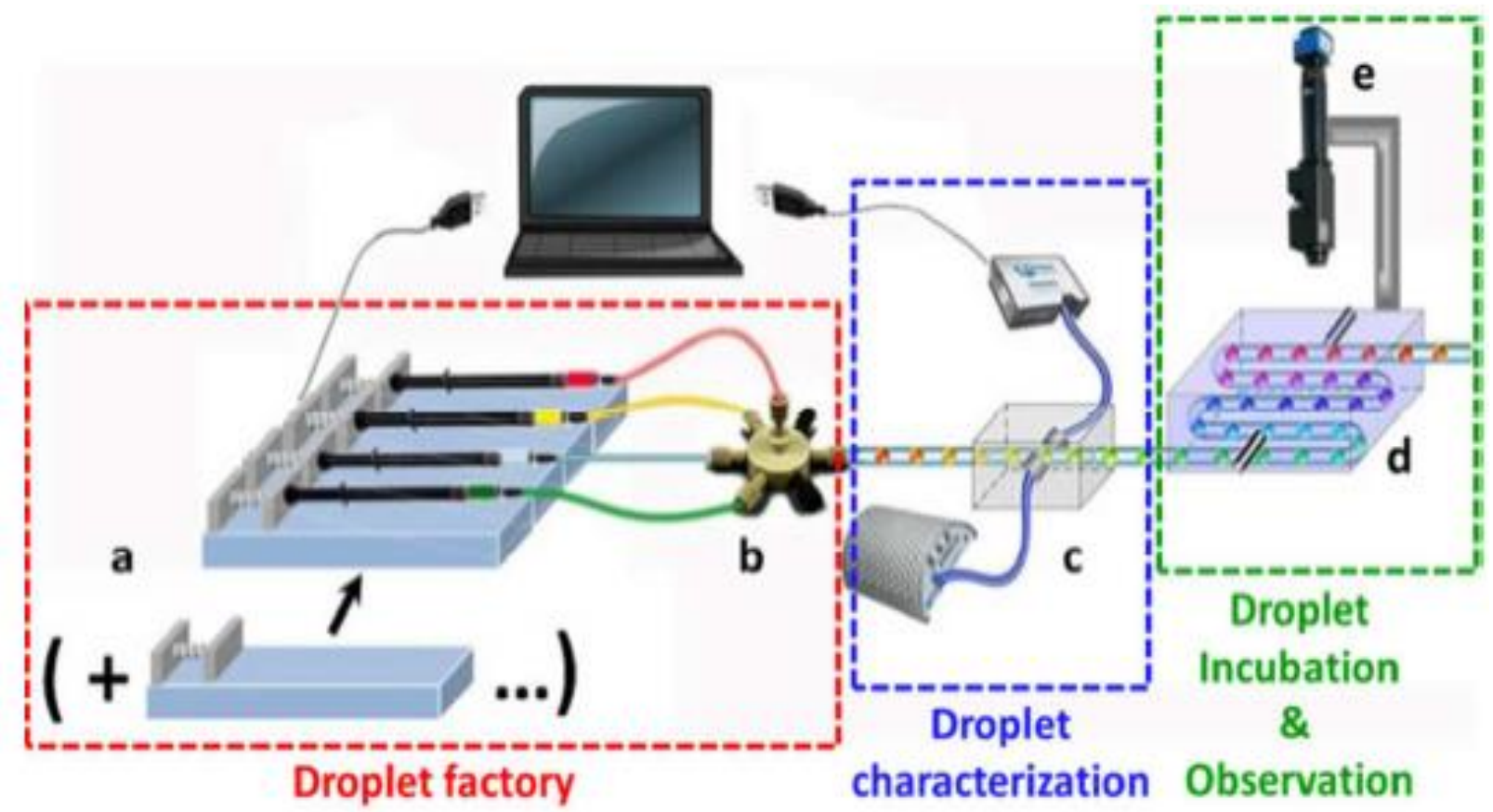

Figure 2. Schematic illustration of our droplet-based microfluidic platform: a) Droplet factory composed of a syringe pump to generate droplets; b) Multiport junction in PEEK (Polyether ether Ketone) and Teflon-like tubing in FEP (fluorinated ethylene propylene); c) Real-time insitu monitoring of droplet characteristics composed of an UV-Vis-NIR spectrophotometer (from 190 to $2300 \mathrm{~nm}$ ), two optical fibers (diameter $400 \mu \mathrm{m}$ ), a light source (from 215 to $2500 \mathrm{~nm}$ ) and a home-made tubing-holder; d) Incubation and observation module composed of a thermostated tubing holder and a camera mounted on an xyz-motorized table with a motorized variable zoom. Reprinted with permission from (29). 

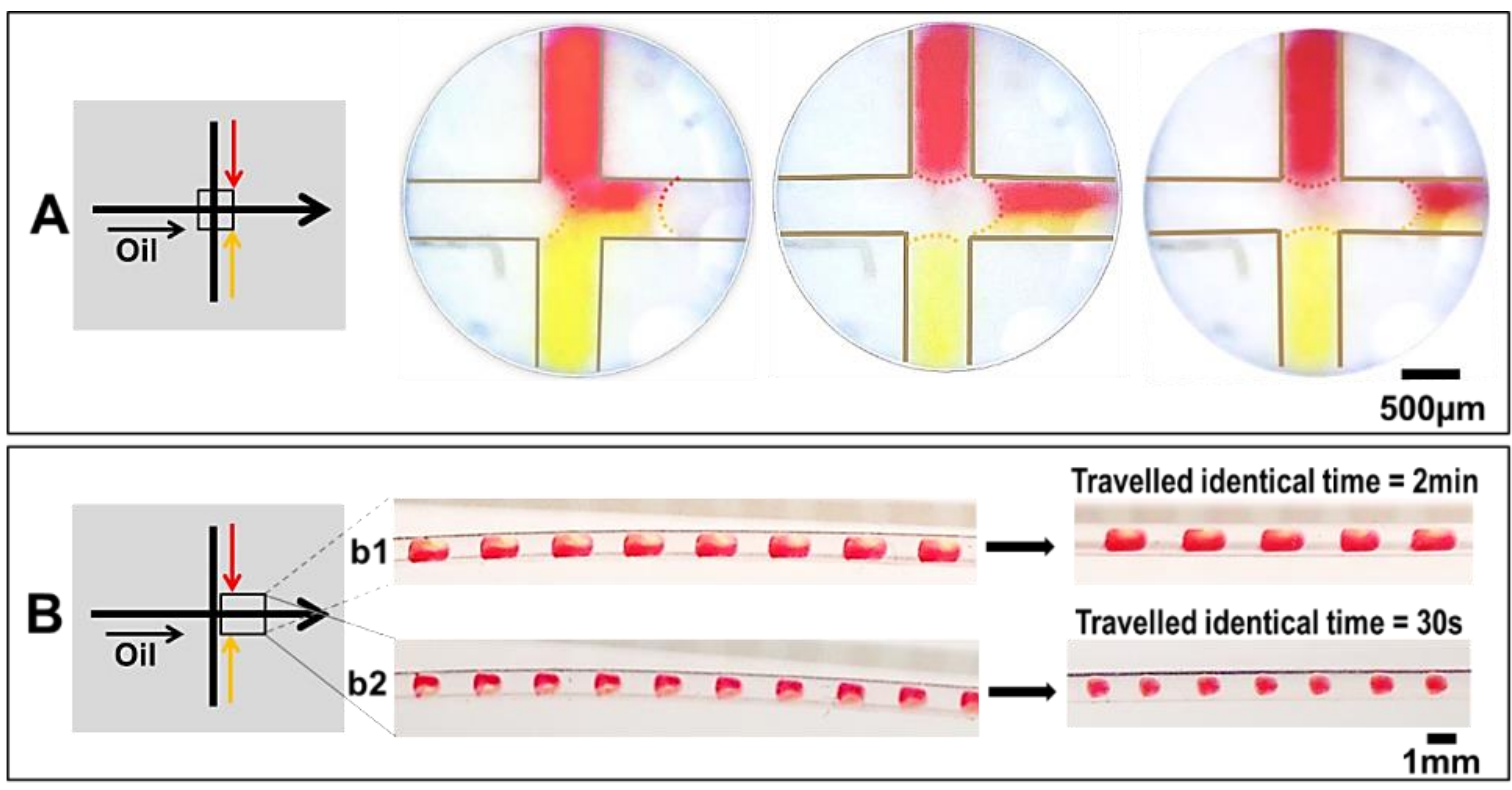

Figure 3. Mix of two dispersed flows in a cross-junction: a) Generation of droplet by injecting two aqueous solutions facing each other in a $1 \mathrm{~mm}$ inner diameter $\mathrm{W}$. The dispersed flows meet and are mixed at the moment when droplets are formed and released into the microfluidic channel by the flow of oil. b) Diffusion time and length $L$ of circulating droplets: b1) 2 minutes for elongated droplets with L/W>2; b2) 30 seconds for spherical droplets with $1 \leq \mathrm{L} / \mathrm{W} \leq 2$. Reprinted with permission from (14). Reprinted with permission from (29). 


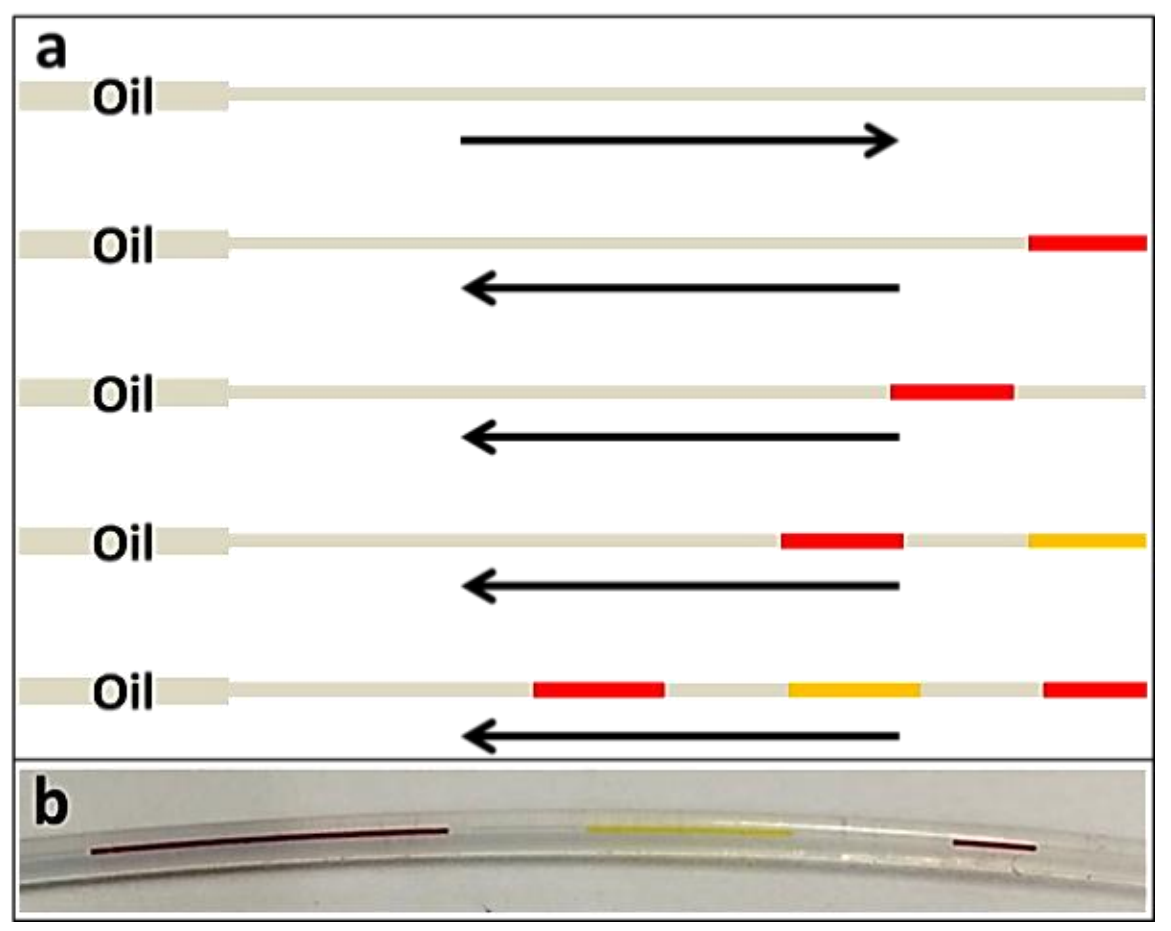

Figure 4: Filling tubing of $150 \mu \mathrm{m}$ inner diameter with different aqueous solutions of yellow and red dyes: a) Schematic illustration of the tubing first filled with the continuous flow (oil in grey), and successively refilled with red and yellow solutions, by interspacing oil between solutions. (b) Picture of tubing with plugs of dye, first of red $(0.22 \mu \mathrm{L})$, then yellow $(0.13 \mu \mathrm{L})$ and then red $(0.05 \mu \mathrm{L})$, separated from each other by an oil spacer to prevent plugs from mixing. Arrows indicate the flow direction. Reprinted with permission from (30). 


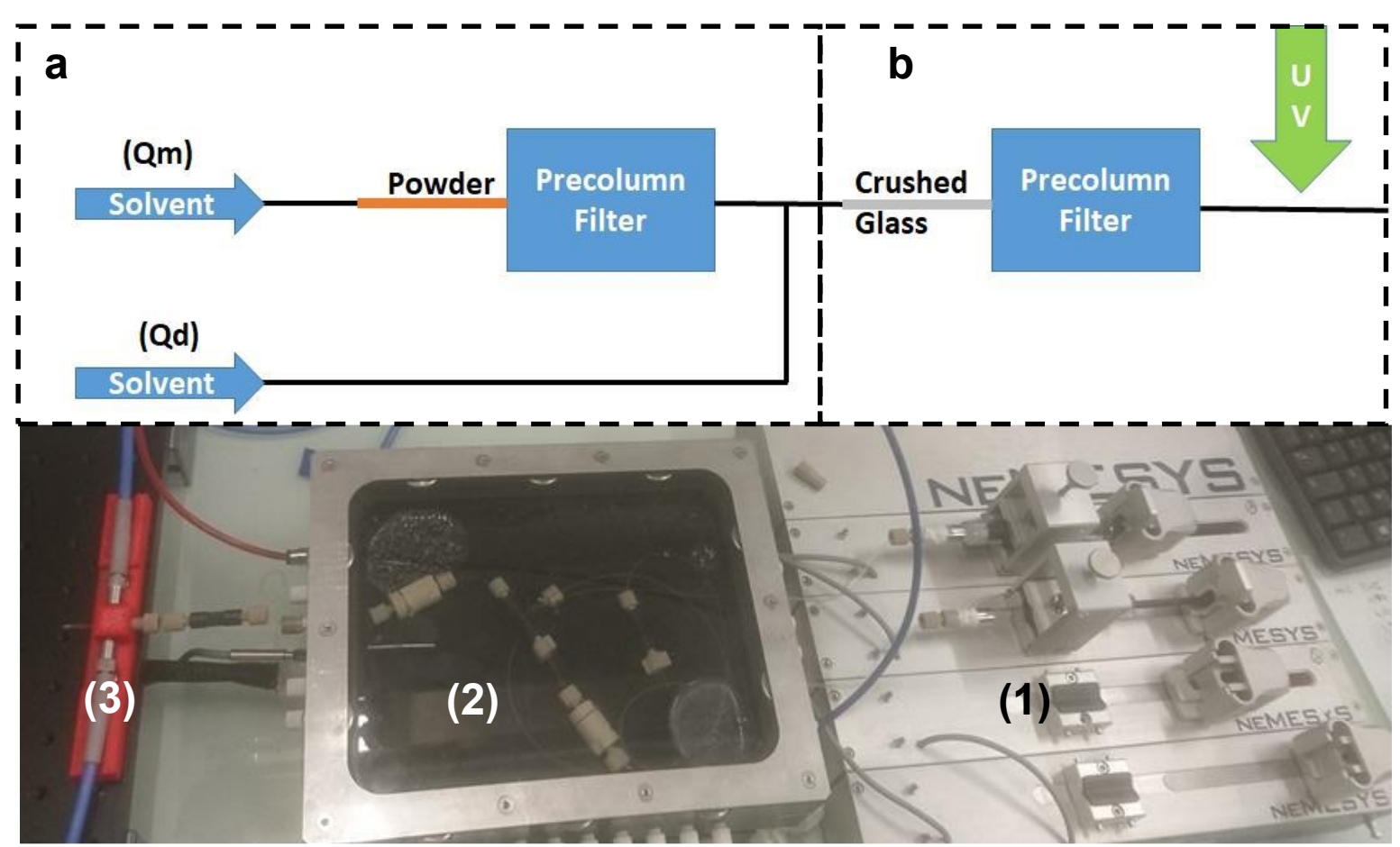

Figure 5. Generation of saturated solution directly from powder in the microfluidic tubing: a) The solvent flowed through a powder placed in $1 \mathrm{~mm}$ inner diameter tubing connected to a precolumn filter of $0.5 \mu \mathrm{m}$. Successive dilutions of the saturated solution were carried out using a T-junction at the outer of the filter. b) The second pre-column filter was filled with crushed glass and added downstream to ensure rapid mixing of solutions. At its outlet, the diluted solution was analyzed by an on-line UV-Vis spectrometer and compared to the absorbance of a

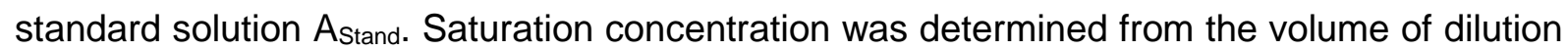
used to reach $A_{\text {Stand. }}$ A bracketing method was used for successive dilution. c) Photograph of the home-made microfluidics set-up: (1) syringe pump, (2) The two columns and the T-junction placed in a temperature-controlled incubator, from room temperature to $65^{\circ} \mathrm{C}$, (3) UV cell. Reprinted with permission from (34). 

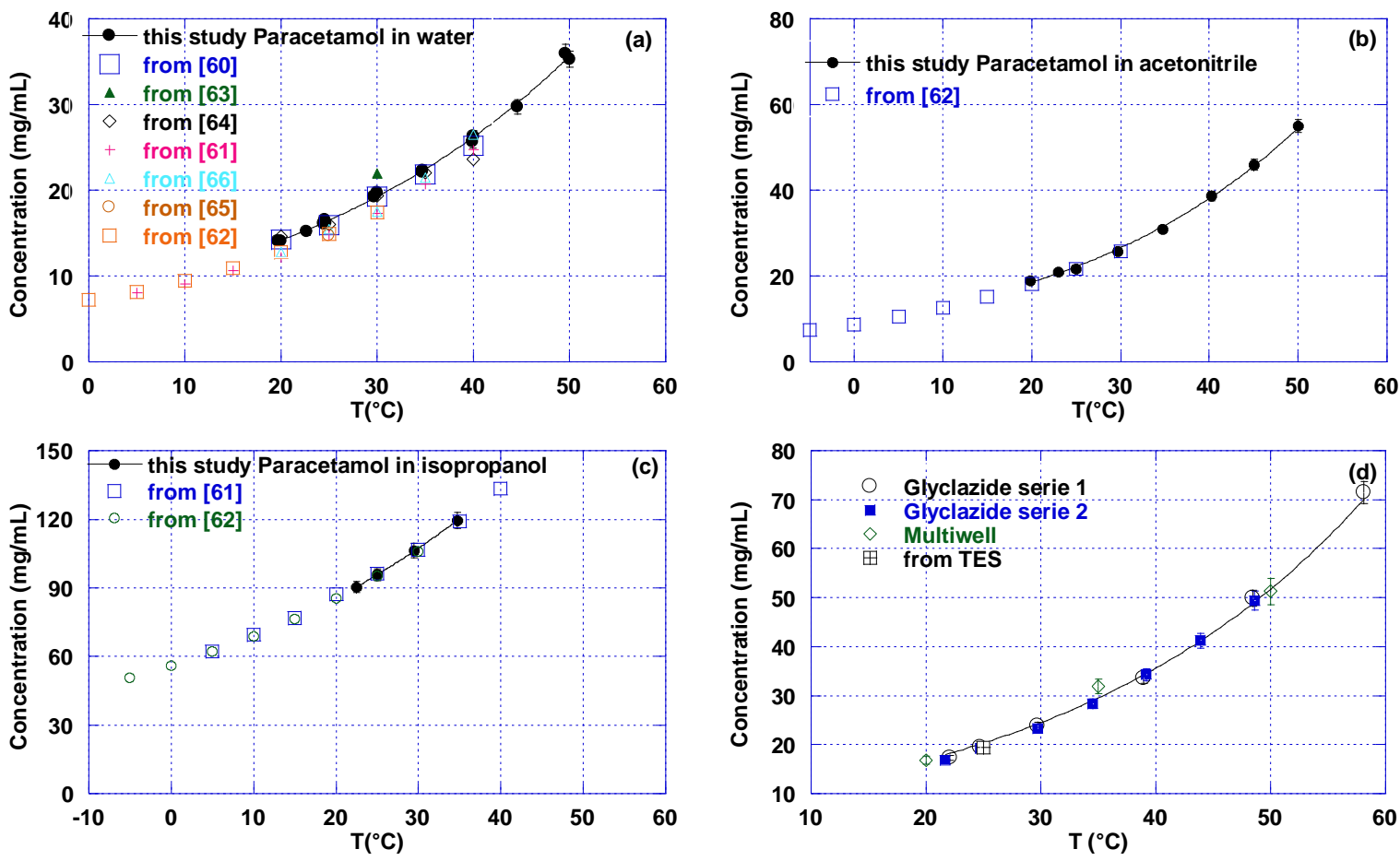

Figure 6. Solubility of Paracetamol compared with measurements realized in large volumes by various techniques: equilibration of a paracetamol suspension at different temperatures and titration of the supernatant by weighing the dry residue (60-62), UV spectrophotometry (6365), or refractive indexes (66): a) in water, b) in acetonitrile, c) in isopropanol. d) Solubility of Glyclazide in acetonitrile after repeating experiments twice, consuming only $30 \mathrm{mg}$ of material at 7 temperatures and taking 4 hours. The methodology of Detoisin et al. with a multiwell setup required more than $250 \mathrm{mg}$ of material at 3 temperatures taking 2 days (67). The curves were exponential fits to our measurements. The error was estimated to $3 \%$ (taking into account powder weighing, UV dosing and syringe pump flow rates). Reprinted with permission from (34). 

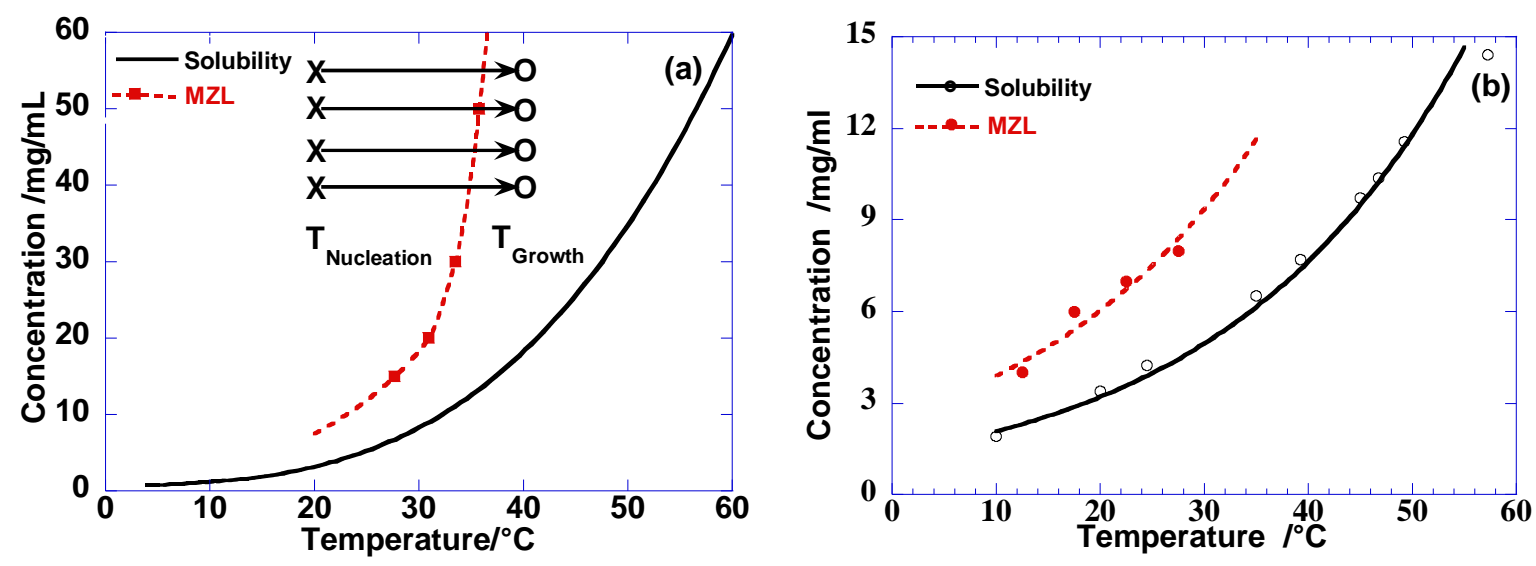

Figure 7. Phase diagram of concentration vs temperature with the solubility curve (-) and the metastable zone limit (MZL) (---), lines improve legibility. For a given concentration, the TMZ, at which there is no crystals, was the corresponding temperature on the MZL. In small volume, the low number of crystals allowed us to count them for each temperature and TMZ was extrapolated (interpolation) from a plot of the number of crystals in the solution vs. temperature. This measurement was performed for several concentrations giving several points of the MZL. Each point corresponded to a statistical treatment on one hundreds of droplets: a) for lysozyme in an aqueous solution; b) for caffeine in ethanol. Reprinted with permission from (21). 

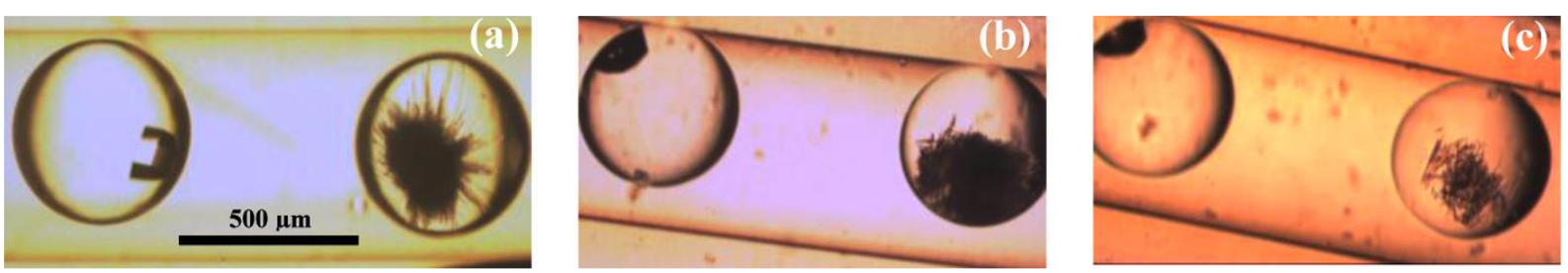

Figure 8: $250 \mathrm{~nL}$ droplets of lysozyme solutions observed at $20^{\circ} \mathrm{C}$ : (a) After a storage of $20 \mathrm{~h}$ at $6^{\circ} \mathrm{C}$. (b) After increasing temperature to $30^{\circ} \mathrm{C}$ during 6 min. (c) After increasing temperature to $30^{\circ} \mathrm{C}$ during $12 \mathrm{~min}$. Reprinted with permission from (22). 


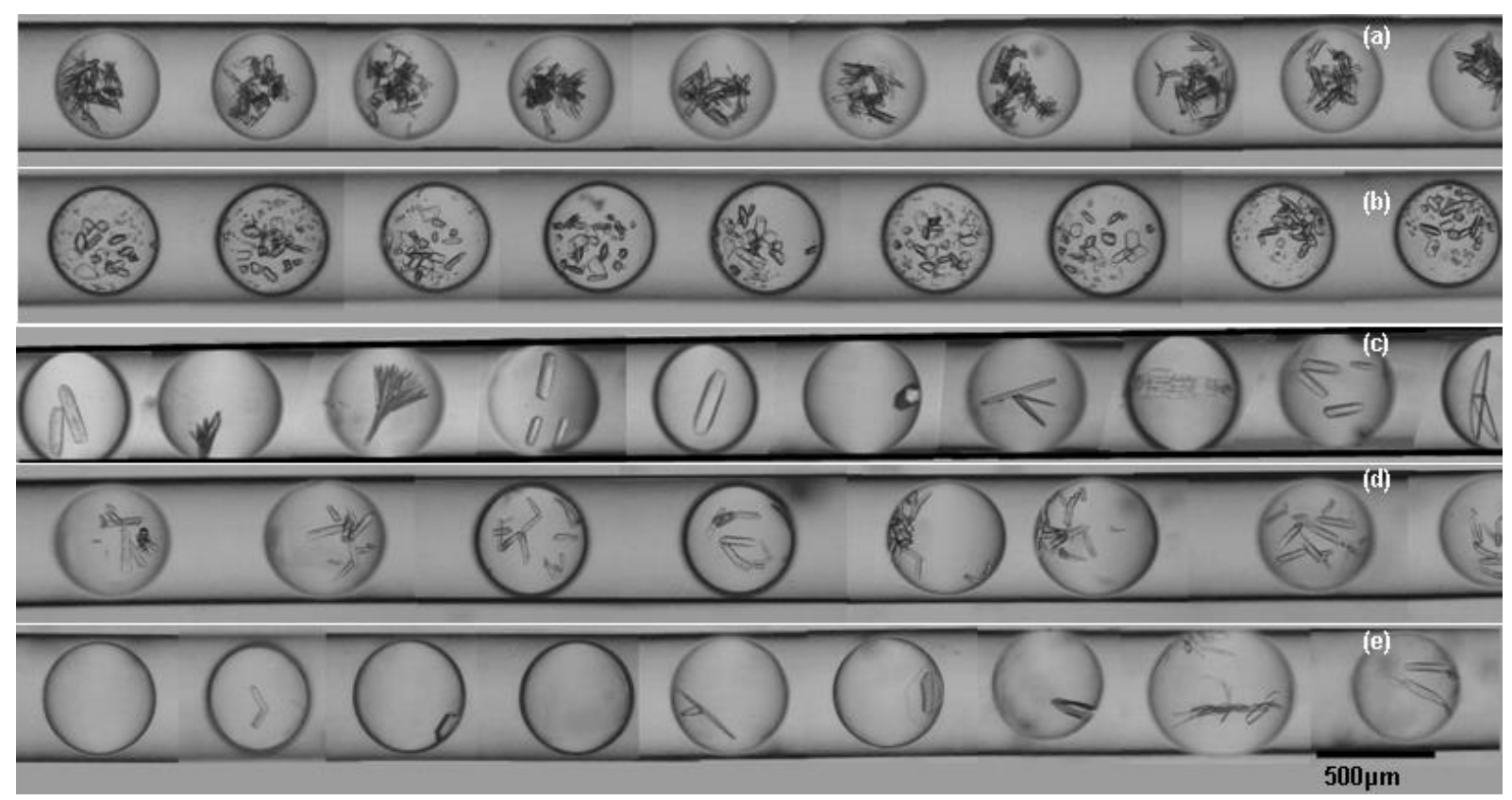

Figure 9. Photos of crystals obtained after $24 \mathrm{~h}$ in $65 \mathrm{~nL}$ droplets of rasburicase with a precipitant agent (PEG), every line corresponds to the same condition: a) $10 \%$ PEG, $10 \mu \mathrm{g} / \mu \mathrm{L}$ rasburicase, at $5{ }^{\circ} \mathrm{C} \mathrm{b)} 10 \%$ PEG, $10 \mu \mathrm{g} / \mu \mathrm{L}$ rasburicase, at $20{ }^{\circ} \mathrm{C}$ c) $5 \%$ PEG, $10 \mu \mathrm{g} / \mu \mathrm{L}$ rasburicase, at $5{ }^{\circ} \mathrm{C}$ d) $7.5 \% \mathrm{PEG}, 5 \mu \mathrm{g} / \mu \mathrm{L}$ rasburicase, at $5{ }^{\circ} \mathrm{C}$ e) $7.5 \%$ de PEG, $5 \mu \mathrm{g} / \mu \mathrm{L}$ rasburicase, at $20^{\circ} \mathrm{C}$. Reprinted with permission from (23). 

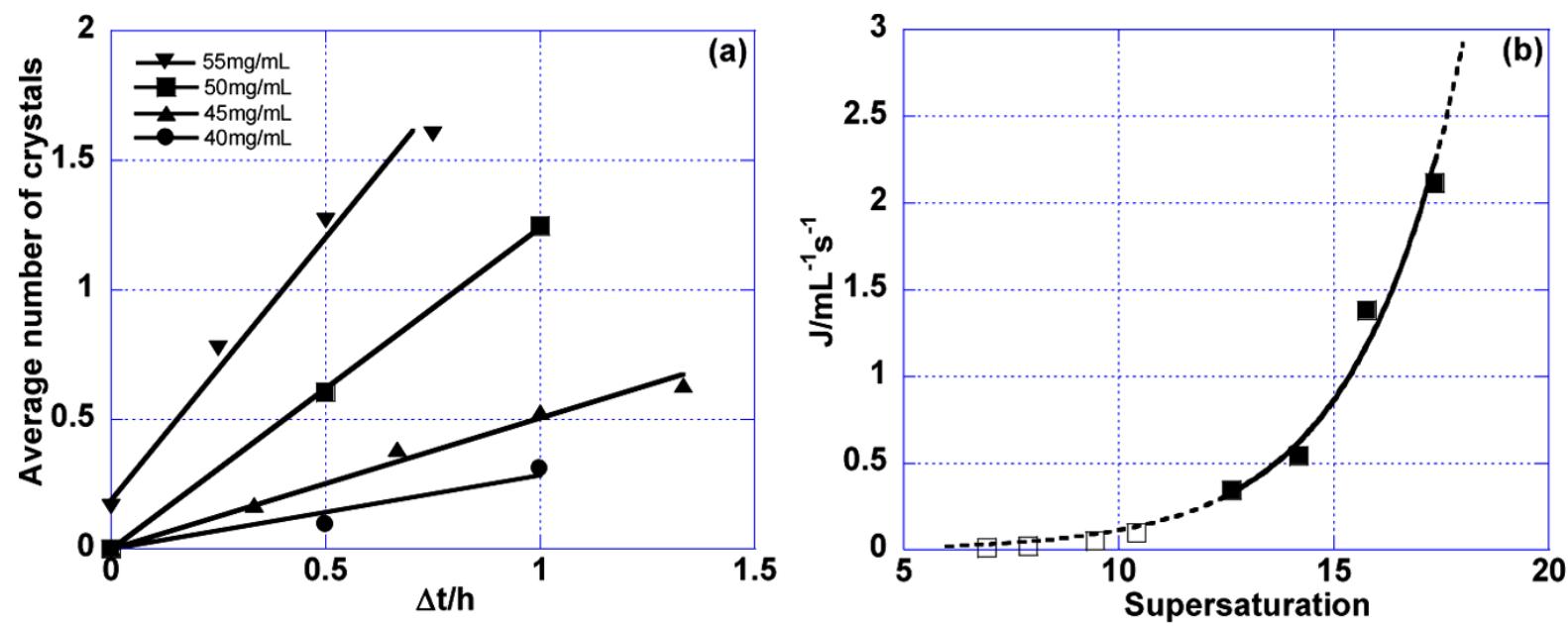

Figure 10. Double Pulse Technique (DPT) to determine the nucleation rate $\mathrm{J}$ for lysozyme. Droplets were first generated at a temperature chosen to prevent nucleation of crystals, $T_{\text {growth }}$. Then the temperature was lowered to $T_{\text {nucleation }}$ to obtain nucleation of crystals. After a period of $\Delta t$ (nucleation time), temperature was raised from $T_{\text {nucleation }}$ to $T_{\text {growth. }}$ At $T_{\text {growth }}$, supersaturation was at a level where the nucleation rate was practically zero, but the crystals already formed could grow to detectable dimensions. After the growth stage, the crystals nucleated at $\mathrm{T}_{\text {Nucleation }}$ during $\Delta \mathrm{t}$ were counted: a) Crystal distribution was fitted with a Poisson law as previously reported by Galkin and Vekilov (78), leading to the average number of crystals nucleated $\mathrm{N}$ in one droplet vs. nucleation time $\Delta$ t. b) Nucleation rate $J$ vs. supersaturation, at $20^{\circ} \mathrm{C}$, from the slope of the straight lines of a); ( $\square$ ) data obtained at $12.6^{\circ}$ from Galkin and Vekilov (78). Reprinted with permission from (33). 


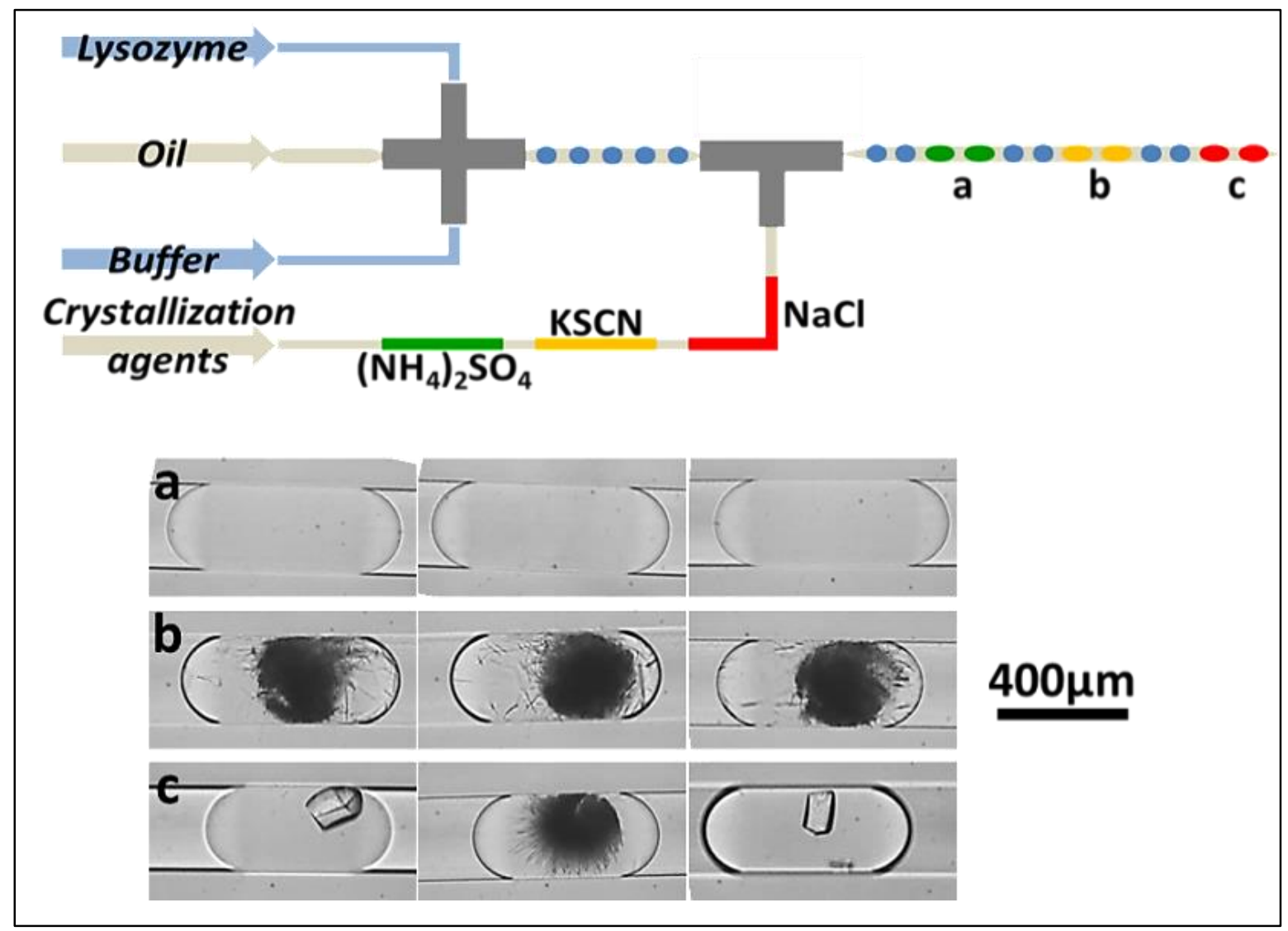

Figure 11: Screening of crystallization agents of lysozyme in $\sim 10 \mathrm{~nL}$ droplets using a "chemical library" of crystallization agents (top scheme) at $20^{\circ} \mathrm{C}$ : a) Adding $\left(\mathrm{NH}_{4}\right)_{2} \mathrm{SO}_{4} 1.1 \mathrm{M}$ yielded no crystallization event. b) Adding KSCN $170 \mathrm{mM}$ led to precipitates of lysozyme in the droplets. c) Adding $\mathrm{NaCl} 1.2 \mathrm{M}$ led to lysozyme crystals with two crystal habits. The first is the tetragonal stable phase and the second, with a sea-urchin-like habit, is a metastable phase (22). About 50 droplets were generated for each condition to check their regularity. Reprinted with permission from (30). 

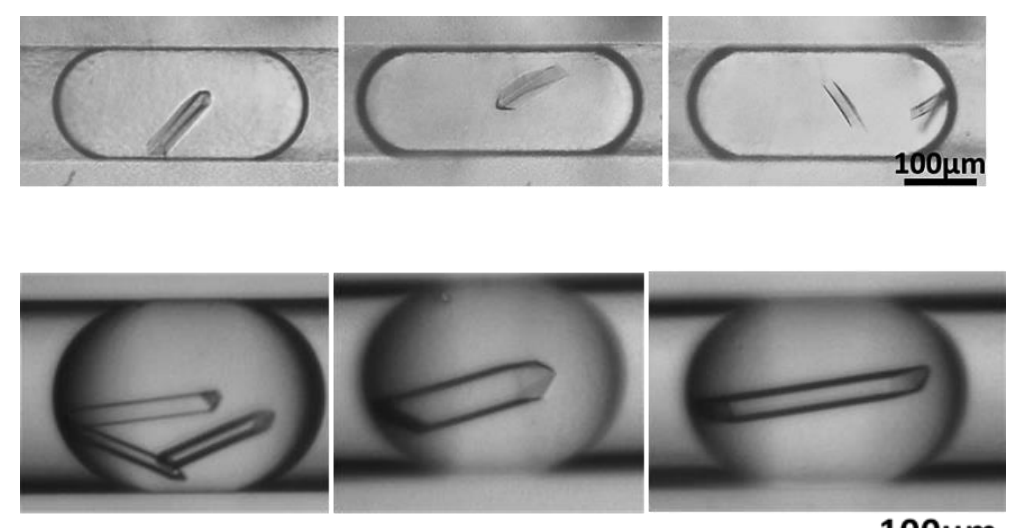

$100 \mu \mathrm{m}$

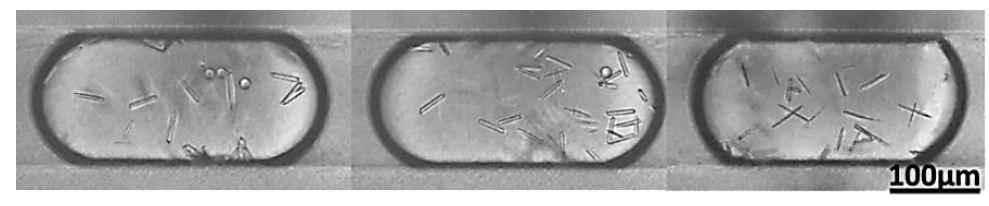

Figure 12: Screening of QR2 (Human Quinone Reductase 2) crystallization conditions in droplets of $n L$ range volume at $20^{\circ} \mathrm{C}$ : a) QR2 crystallization in presence of $8 \%$ DMSO (30); b) QR2 crystallization in aqueous solution (32); c) QR2 co-crystallization with melatonine in presence of 7\% DMSO (30). Reprinted with permission from (30). 


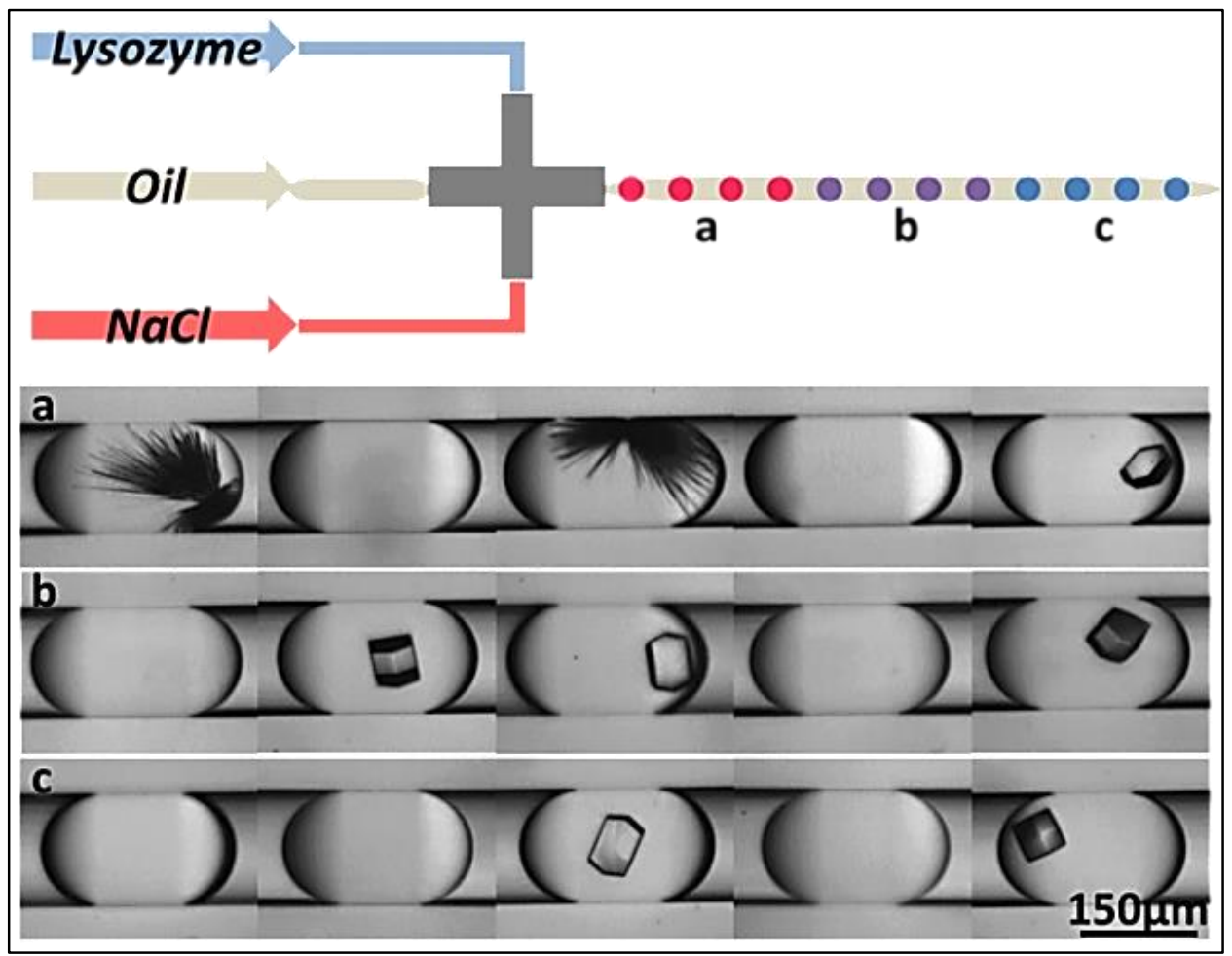

Figure 13. Optimization of crystallization conditions of lysozyme in a buffer varying their respective flows rate (top scheme) at $15^{\circ} \mathrm{C}$ : a) Lysozyme $23 \mathrm{mg} / \mathrm{mL}, 1.33 \mathrm{M} \mathrm{NaCl}$, b) Lysozyme $35 \mathrm{mg} / \mathrm{mL}, 1 \mathrm{M} \mathrm{NaCl}, \mathrm{c})$ Lysozyme $47 \mathrm{mg} / \mathrm{mL}, 0.66 \mathrm{M} \mathrm{NaCl}$. Reprinted with permission from (30). 

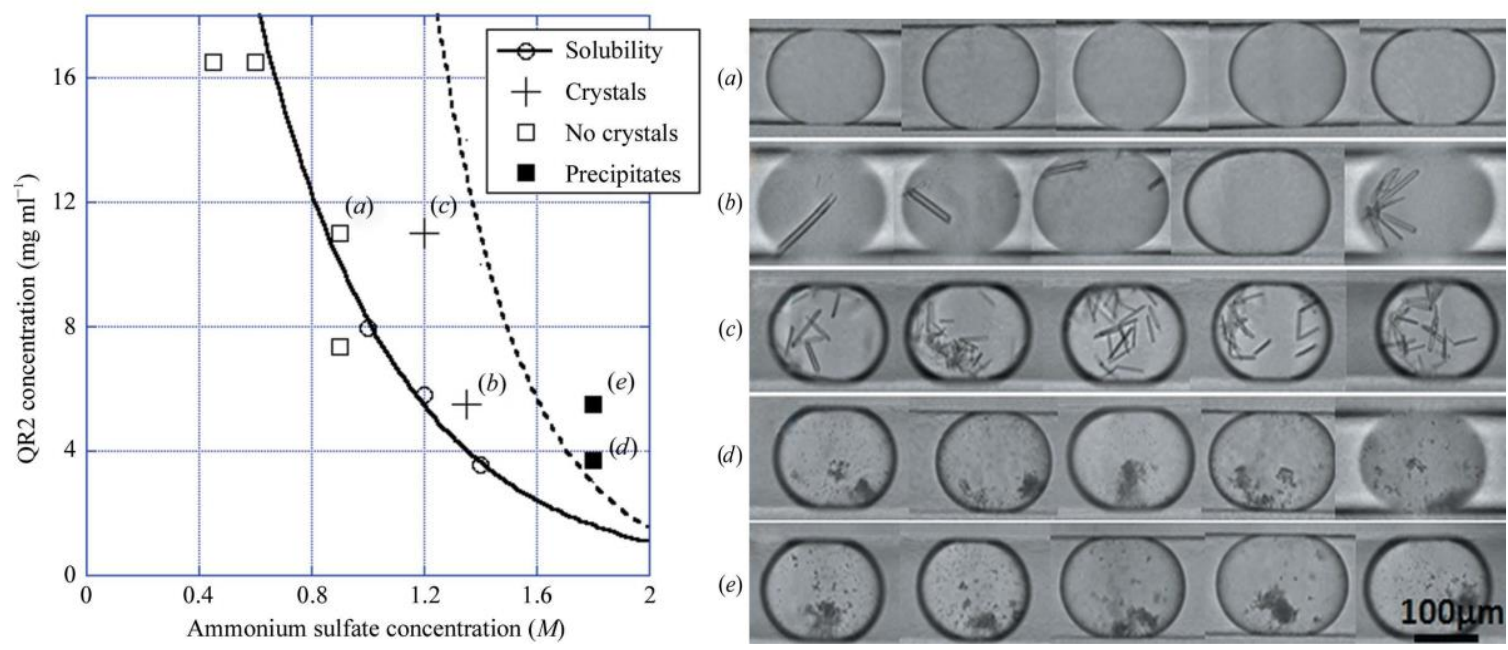

Figure 14. Left, phase diagram of QR2 (Human Quinone Reductase 2) versus ammonium sulfate at $20^{\circ} \mathrm{C}$ and the different experimental conditions tested in the fine-gradient experiment; the dashed line is a guide for the eye to separate the crystallization and precipitation zones. Right, photographs of five representative droplets for each condition: a) $11 \mathrm{mgm}$ I $^{-1} \mathrm{QR} 2,0.9 \mathrm{M}$ ammonium sulfate, b) $5.5 \mathrm{mg}^{\mathrm{ml}}{ }^{-1} \mathrm{QR} 2,1.35 \mathrm{M}$ ammonium sulfate, c) $11 \mathrm{mg} \cdot \mathrm{ml}^{-1} \mathrm{QR} 2,1.2 \mathrm{M}$

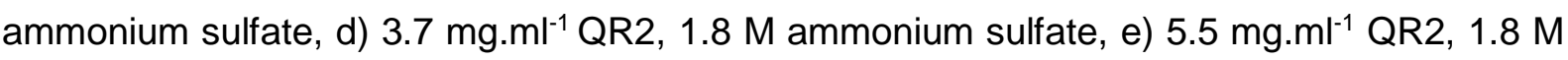
ammonium sulfate. Reprinted with permission from (32). 

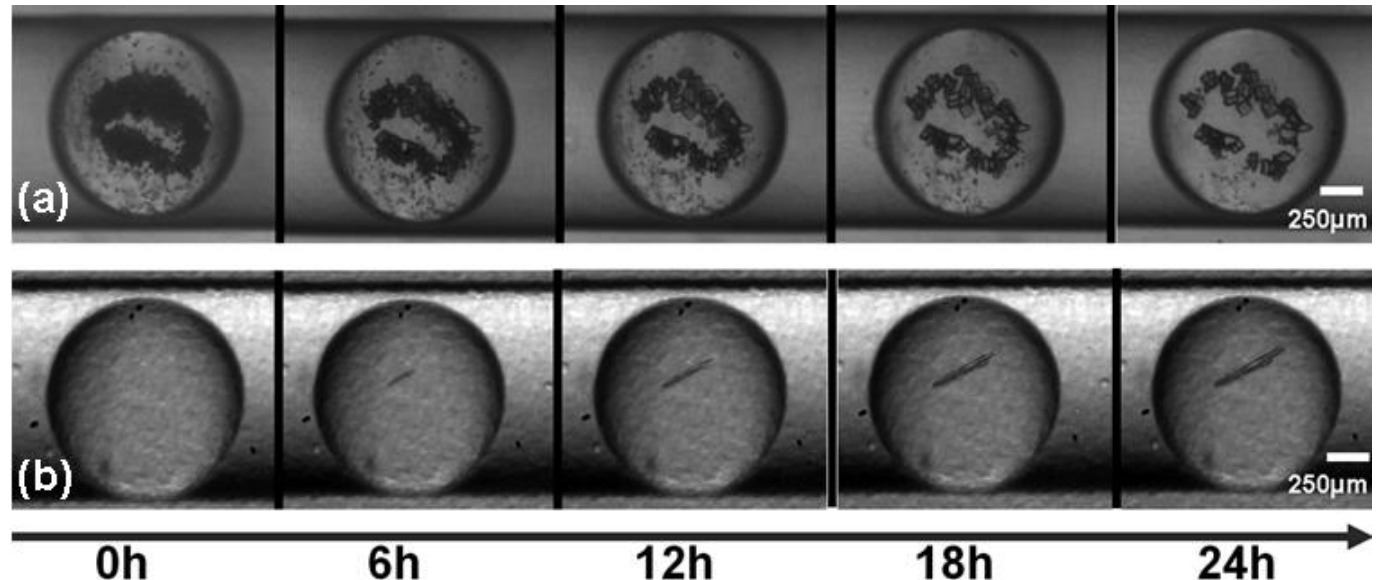

Figure 15. Time sequence of droplets of rasburicase in PEG (polyethylene glycol) for $24 \mathrm{~h}$ storage. (a) $10 \%$ PEG, $10 \mu \mathrm{g} / \mu \mathrm{L}$ rasburicase, at $20^{\circ} \mathrm{C}$. (b) $7.5 \% \mathrm{PEG}, 2 \mu \mathrm{g} / \mu \mathrm{L}$ rasburicase, at $20^{\circ} \mathrm{C}$. Reprinted with permission from (23). 


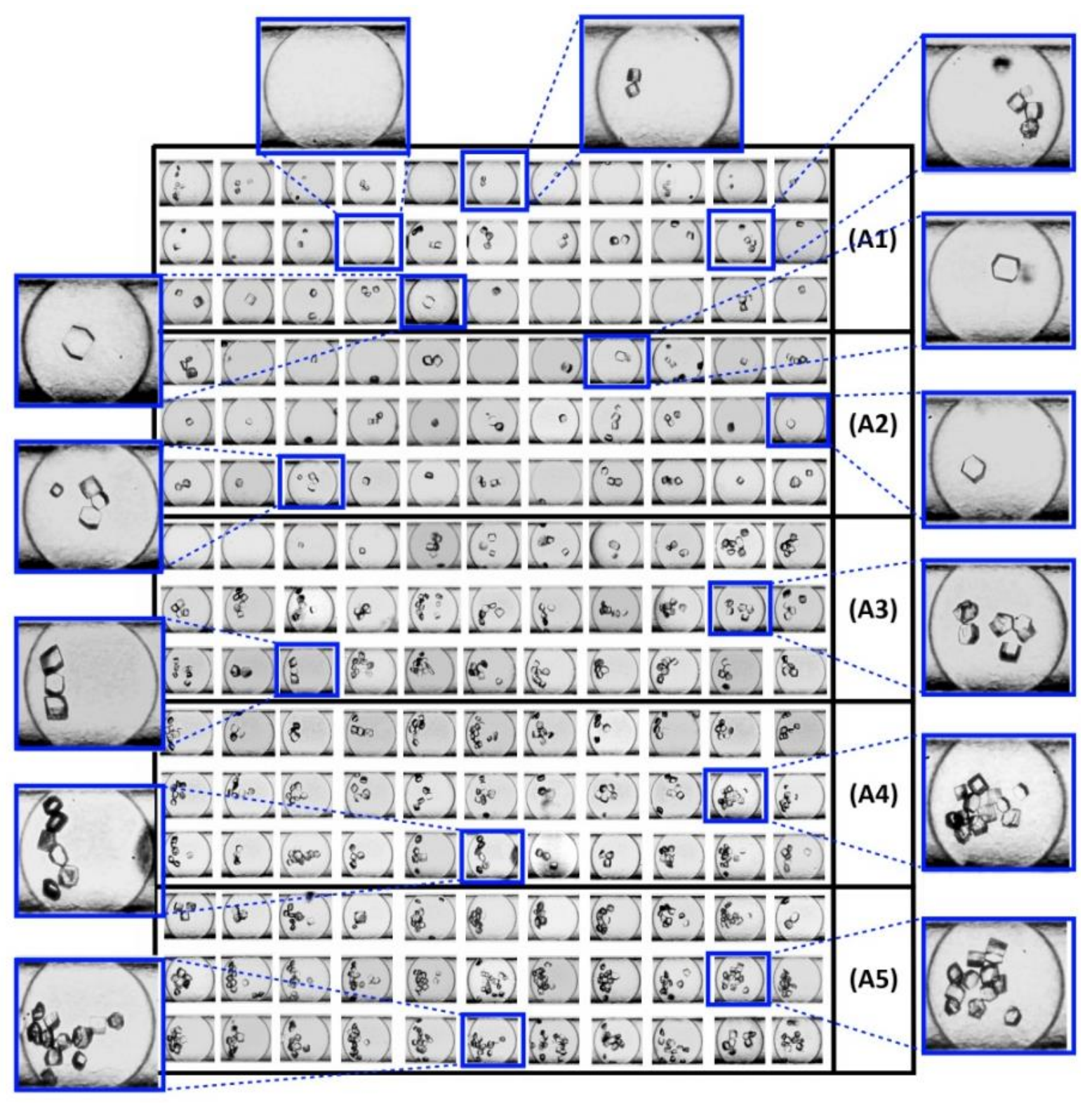

Figure 16. Fine-gradient optimization of lysozyme crystallized in aqueous solutions of PEG (polyethylene glycol) and $\mathrm{C}_{10} \mathrm{E}_{5}$ (pentaethylene glycol monodecyl ether) with a 5-step concentration gradient of lysozyme leading to a mapping of crystal morphogram: (A1) $5 \mathrm{mg} / \mathrm{mL}$, (A2) $7.5 \mathrm{mg} / \mathrm{mL}$, (A3) $10 \mathrm{mg} / \mathrm{mL}$, (A4) $12.5 \mathrm{mg} / \mathrm{mL}$ and (A5) $15 \mathrm{mg} / \mathrm{mL}$. Reprinted with permission from (29). 

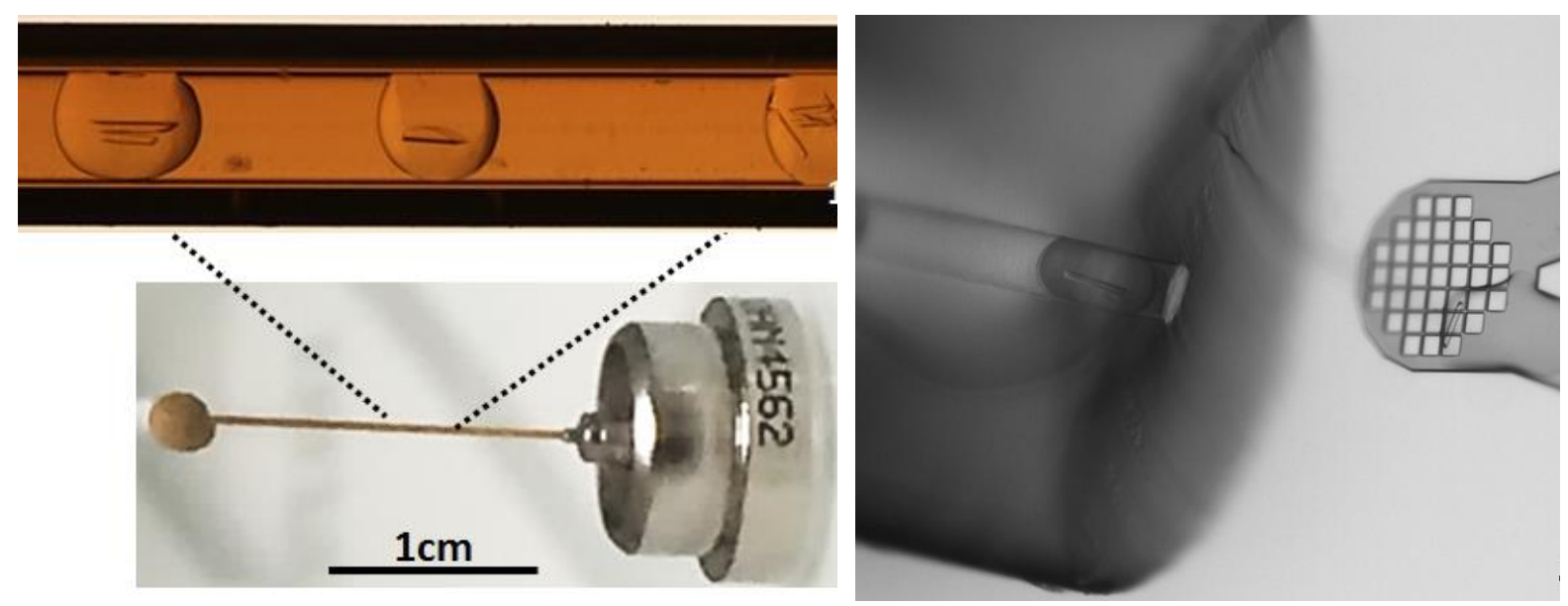

Figure 17. X-ray diffraction (XRD) of QR2 (Human Quinone Reductase 2) crystals: a) Photographs of the silica tubing with QR2 crystals mounted on a magnetic base for in-situ XRD. b) Photograph of a crystal of QR2 in a droplet deposited on the MicroMesh for ex-situ XRD. Reprinted with permission from (32). 